\title{
The Regulation of Trophoblastic p53 Homeostasis by the p38-Wip1 Feedback Loop is Disturbed in Placentas from Pregnancies Complicated by Preeclampsia
}

\author{
Bin Tan ${ }^{a, b, c}$ Chao Tong ${ }^{a, b, c} \quad$ Yu Yuann ${ }^{a, b, c}$ Ping Xu $u^{a, b, c} \quad$ Li Wen ${ }^{a, b, c} \quad$ Chen Zhang ${ }^{a, b, c}$ \\ Yangxi Zheng ${ }^{a, b, c}$ Li Lin ${ }^{a, b, c}$ Fangyu Zhu $u^{a, b, c}$ Shunping Guia, ${ }^{a, b}, \quad$ Lianlian Wang ${ }^{b, d}$ \\ Rufei Gao ${ }^{b, e}$ Jie Lia,b,c Hongbo Qja,b,c Philip N. Baker ${ }^{b, e, f}$
}

aDepartment of Obstetrics, The First Affiliated Hospital of Chongqing Medical University, Chongqing, China, 'International Collaborative Laboratory of Reproduction and Development, Ministry of Education, Chongqing, China, 'State Key Laboratory of Maternal and Fetal Medicine of Chongqing Municipality, Chongqing, China, dDepartment of Reproduction Health and Infertility, The First Affiliated Hospital of Chongqing Medical University, Chongqing, China, eLaboratory of Reproductive Biology, School of Public Health and Management, Chongqing Medical University, Chongqing, China, ${ }^{\mathrm{f} C o l l e g e}$ of Life Sciences, University of Leicester, Leicester, United Kingdom

\section{Key Words}

Wip1 • p53 • p38 • Apoptosis $・$ Preeclampsia

\begin{abstract}
Background/Aims: Excessive apoptosis of trophoblasts, induced by sustained hypoxia, leads to abnormal placentation and is strongly linked to pregnancy complications such as preeclampsia (PE). Wild-type p53-induced phosphatase (Wip1) positively regulates cellular survival in tumor cells through the p38 and p53 pathways, but its expression pattern and effects in trophoblasts have yet to be reported. This study clarified the effect of Wip1 on the regulatory mechanism of p53-dependent apoptosis in trophoblasts, and thus increases understanding of the etiology of PE. Methods: In normal and PE placentas, Wip1 mRNA and protein levels were determined by RT-qPCR and Western blotting respectively, while localization of Wip1 in placental tissues and in HTR8/SVneo cells was determined by immunohistochemistry and immunofluorescence. Two in vitro trophoblastic PE models were established by subjecting HTR8/SVneo cells to either hypoxia intervention in incubator (HII) or simulated ischemic buffer (SIB). Wip1 was suppressed in the aforementioned PE models by specific inhibitor or shRNA, and apoptosis was then assessed by flow cytometry, while further validation was done by measurement of cleaved-caspase 9 expression by Western blotting. The p38 inhibitor SB202190, Mdm2 inhibitor NVP-CGM097, and proteasome inhibitor MG-

B. Tan and C. Tong contributed equally to this work.

\begin{tabular}{ll}
\hline Dr. Chao Tong & Department of Obstetrics, The First Affiliated Hospital of Chongqing Medical University \\
and Dr. Hongbo Qi & 1 Youyi Road, Yuzhong District, Chongqing 400016 (China) \\
& Tel: +862389011101;+862389011865, E-Mail chaotongcqmu@163.com; qihongbo728@163.com
\end{tabular}
\end{abstract}


132 were administered in PE models, either in combination or alone, to determine the regulatory order of the component signal molecules of the feedback loop. The impact of Wip1 on p53-Mdm2 interaction was examined by coimmunoprecipitation. Lastly, the upregulation of the p38-Wip1 loop was confirmed in human placentas from pregnancies complicated by $\mathrm{PE}$, using Western blotting. Results: Wip1 expression was significantly elevated in human PE placentas and in vitro trophoblastic PE models; this is opposite to the pattern observed in tumor cells. Inhibition of Wip1 rescued hypoxia-induced p38 activation, cleavage of caspase 9 and apoptosis but significantly compromised p53-Mdm2 binding, while p-p53 Ser15 was increased. Inhibition of Mdm2 degradation resulted in p53 destabilization and p38-Wip1 loop down-regulation, while degradation of the $\mathrm{p} 53-\mathrm{Mdm} 2$ complex resulted in $\mathrm{p} 53$ accumulation and p38-Wip1 loop hyperactivation. However, the p53-Mdm2 interaction was found to be more important in the regulation of the p38-Wip1 loop than Mdm2 stability. Conclusion: Trophoblastic p53 homeostasis is maintained by the p38-Wip1 feedback regulatory loop in response to hypoxic stress, which is dysregulated in the placentas of pregnancies complicated by $P E$, and thereby leads to excessive apoptosis.

(C) 2019 The Author(s)

Published by S. Karger AG, Basel

\section{Introduction}

The proliferation, differentiation and invasion of trophoblasts are key to a successful pregnancy $[1,2]$. During the first trimester, cytotrophoblasts (CTBs) rapidly proliferate and further differentiate into syncytiotrophoblasts (STBs) and extravillous trophoblasts (EVTs). In addition to implantation into the myometrium, EVTs invade spiral arteries in the maternal uterus, contributing to the establishment of a fetomaternal circulation to meet the nutrient and oxygen demand for fetal development. Defects in remodeling of the uterine spiral arteries result in the aberrant release of inflammatory factors as pregnancy progresses, eventually resulting in the development of preeclampsia (PE)[3] and intrauterine growth restriction (IUGR)[4].

In human placentas, trophoblastic dysfunction is associated with apoptosis induced by pathological hypoxia [5-7]. The expression of the tumor suppressor, p53, is inhibited by mouse double minute 2 homolog (Mdm2), and this presents a classical negative feedback loop, which is upregulated in response to conditions of stress, as well as in hypoxic trophoblasts [8]. Although a large number of studies have sought to elucidate the etiology of PE, the involvement of p53-Mdm2 in PE development through regulation of trophoblastic apoptosis remains largely unclear.

As a stress-activated protein kinase (SAPK), p38 mitogen-activated protein kinase (MAPK) has been reported to be involved in the regulation of inflammation, tumorigenesis, cardiovascular, and neurodegenerative diseases by modulating cellular survival and apoptosis [9]. Accumulating evidence suggests that wild-type p53-induced phosphatase (Wip1) negatively regulates p38 activity in various cancer cells by dephosphorylation [10, 11]. Wip1 is encoded by the PPM1D (protein phosphatase $\mathrm{Mg}^{2+} / \mathrm{Mn}^{2+}$ dependent 1D) gene located on chromosome 17q23.2, and was found to play an important role in the pathogenesis of several diseases [12-14], especially in tumorigenesis [15-17]. Although current evidence suggests that Wip1-mediated pathological progression occurs through negative regulation of the p53 by p38 pathways during tumorigenesis [18], its role in trophoblasts has yet to be delineated.

Wip1 reduces p53 by directly dephosphorylating p53 on Ser15 as a result of increased interaction between p53 and Mdm2 [19, 20]. Additionally, Wip1 inactivates p38 through a dephosphorylation of Thr180/Tyr182 in tumor cells undergoing stress [21]. Both of these findings imply that Wip1 might play a crucial role in the crosstalk between p53 and p38, protecting against the impact of various stresses on trophoblastic viability during pregnancy. Hence, this study aimed to unveil the involvement of Wip1 in the regulatory mechanism of p53-dependent trophoblastic death, and the findings may provide insights into the etiology of PE. 


\section{Cellular Physiology Cell Physiol Biochem 2019;52:315-335 \\ \begin{tabular}{l|l|l}
\hline DOI: 10.33594/000000023 & (c) 2019 The Author(s). Published by
\end{tabular} \\ \begin{tabular}{l|l} 
Published online: 28 February 2019 & Cell Physiol Biochem Press GmbH\&Co. KG \\
\hline
\end{tabular} \\ Tan et al.: p38-Wip1 Loop Regulates p53 in Trophoblast}

\section{Materials and Methods}

\section{Patient recruitment}

Women with PE and healthy normotensive pregnant women were recruited from the Department of Obstetrics at The First Affiliated Hospital of Chongqing Medical University. PE was defined as hypertension reaching or exceeding $140 / 90 \mathrm{mmHg}$ on two or more occasions after 20 weeks of gestation, without preexisting hypertension [22]. Women with chronic medical conditions such as cardiovascular diseases, diabetes, renal disorders, intrahepatic cholestasis of pregnancy (ICP), thyroid disorders, and other metabolic diseases were excluded. All pregnancies in this study were delivered by elective cesarean section for obstetric indications. This study was conducted in accordance with the principles set out in the Declaration of Helsinki and approved by the Ethical Committee of Chongqing Medical University (No. 201678). Informed consent was obtained from all participants.

\section{Sample collection}

Collection of term placental specimens was performed as previously described [23]. Briefly, tissues were dissected from the maternal surface of the placenta that was close to the basal decidua and surrounding umbilical cord insertion. This was done immediately after cesarean section, and visible infarction, calcification, hematoma, or tears were avoided. Placental tissue from each participant was immersed in RNAlater (QIAGEN, Hilden, Germany) and snap-frozen in liquid nitrogen (after rinsing thoroughly in ice-cold $0.9 \%$ saline), and then stored at $-80^{\circ} \mathrm{C}$. The remaining placental tissues were fixed in a $4 \%$ formaldehyde solution. Human decidual and villus tissues were obtained under aseptic conditions from healthy women who voluntarily chose legal abortions during the first trimester (5-10 weeks of gestation) for nonmedical reasons.

\section{Immunohistochemistry (IHC)}

IHC was performed on paraffin-embedded specimens as reported [24]. First-trimester villus and term placental sections were incubated with the primary cytokeratin-7 (CK7) antibody (1:200, Abcam, Cambridge, UK). The decidual sections were incubated with the primary antibody (1:200, Proteintech, Rosemont, USA) against human leukocyte antigen G (HLA-G). Meanwhile, the corresponding serial sections were incubated with primary Wip1 antibody (1:1000, Abcam, Cambridge, UK) and the term placental section had an additional incubation in the primary CD31 antibody (1:200, Abcam, Cambridge, UK). Following incubation overnight at $4^{\circ} \mathrm{C}$, sections were incubated with horseradish peroxidase-conjugated anti-rabbit or anti-mouse secondary antibody (1:500, Proteintech, Rosemont, USA) and sequentially stained with diaminobenzidine chromogen solution (DAB). Cell nuclei were counterstained with hematoxylin.

\section{Cell line and hypoxic treatments}

The HTR8/SVneo cell line was a generous gift from Dr. Charles Graham (Queen's University, Kingston, Ontario, Canada). Cells were cultured in RPMI 1640 medium (Thermo Fisher, Waltham, USA) supplemented with $10 \%$ fetal bovine serum (Thermo Fisher, Waltham, USA) and 1\% penicillin-streptomycin in a humidified atmosphere of $21 \% \mathrm{O}_{2}$ and $5 \% \mathrm{CO}_{2}$ at $37^{\circ} \mathrm{C}$. Cells subjected to persistent $(24 \mathrm{~h})$ low-oxygen $\left(1 \% \mathrm{O}_{2}\right)$ were denoted as hypoxia intervention in incubator (HII), while simulated ischemic buffer (SIB) containing 137 $\mathrm{mM} \mathrm{NaCl}, 12 \mathrm{mM} \mathrm{KCl}, 0.49 \mathrm{mM} \mathrm{MgCl}_{2}, 0.9 \mathrm{mM} \mathrm{CaCl}_{2}$, $4 \mathrm{mM}$ HEPES, $10 \mathrm{mM}$ deoxyglucose, $0.75 \mathrm{mM}$ sodium dithionate, and $20 \mathrm{mM}$ lactate ( $\mathrm{pH}$ 6.5) was applied to HTR8/SVneo cells for $24 \mathrm{~h}$ in a humidified incubator $\left(21 \% \mathrm{O}_{2}, 5 \% \mathrm{CO}_{2}, 37^{\circ} \mathrm{C}\right)$ as previously described [25].

\section{Immunoblotting}

Cells and placental tissues were lysed in RIPA lysis buffer (Sigma Aldrich, St. Louis, USA) supplemented with both protease inhibitor (Selleckchem, Houston, USA) and phosphatase inhibitor cocktails (Selleckchem, Houston, USA). Protein concentrations were determined by the use of a BCA assay kit (Beyotime, Beijing, China) according to the manufacturer's manual. Then, $20 \mu \mathrm{g}$ of total proteins was subjected to $7 \%$ or $10 \%$ discontinuous SDS-PAGE and transferred to polyvinylidene fluoride membranes (Roche, UK). Membranes were blocked for $1 \mathrm{~h}$ with 5\% nonfat dried milk in Tris-buffered saline containing 0.05\% Tween-20 (TBST) and then probed with primary antibodies at $4^{\circ} \mathrm{C}$ overnight. Primary antibodies against p-AMPK ${ }^{\mathrm{Th} 172}$ (1:1000), AMPK $\alpha$ (1:1000), p-ACC ${ }^{\text {Ser79 }}$ (1:1000), ACC (1:1000), p-p53 ${ }^{\text {Ser15 }}$ (1:1000), p-p38 ${ }^{\text {Thr180/Tyr182 }}$ (1:1000), 


\section{Cellular Physiology Cell Physiol Biochem 2019;52:315-335 \\ \begin{tabular}{l|l|l}
\hline DOI: 10.33594/000000023 & (c) 2019 The Author(s). Published by
\end{tabular} \\ and Biochemistry Published online: 28 February 2019 Cell Physiol Biochem Press GmbH\&Co. KG \\ Tan et al.: p38-Wip1 Loop Regulates p53 in Trophoblast}

p38 (1:1000), and cleaved caspase-9 (cl-cas9, 1:1000) were purchased from Cell Signaling Technology (Danvers, USA); p53 (1:2000) and $\beta$-actin (1:1000) were purchased from Proteintech (Rosemont, USA); Wip1 (1:1000) and Mdm2 (1:1000) were purchased from Abcam (Cambridge, UK) and Invitrogen (Waltham, USA), respectively. The membranes were then washed three times in TBST, each time for $10 \mathrm{~min}$, followed by incubation with anti-rabbit (1:5000, Proteintech) or anti-mouse (1:5000, Proteintech) IgG secondary antibody conjugated with horseradish peroxidase. The immunoreactive signal was then detected by ECL reagents (Millipore, Darmstadt, Germany), and the bands were scanned and quantified by densitometry analysis using an image analyzer Quantity One System (Bio-Rad, Richmond, CA, USA).

\section{Real-time reverse-transcriptase quantitative polymerase chain reaction (RT-qPCR)}

Total RNA of the placental tissue was extracted using TRIzol reagent (Invitrogen, Waltham, USA) followed by measurement of the RNA concentration by NanoDrop 2000 (Thermo Fisher, Waltham, USA). cDNA was obtained from total RNA by reverse transcription with the Superscript II First-Strand Synthesis System (Roche, Basel, Switzerland). The primer sequences for RT-qPCR were designed as follows:

PPM1D forward: 5'-GTGGAAGAAACTGGCGGAATG-3', reverse: 5'-ACCACCCCTGAGTCACCTACG-3'; $\beta$-actin forward: 5'-TGGCACCCAGCACAATGAA-3', reverse:5'-CTAAGTCATAGTCCGCCTAGAAGCA-3'.

mRNA levels were quantified by using SYBR Green I and melting curve analysis to ensure amplification specificity through the Bio-Rad CFX Connect ${ }^{\mathrm{TM}}$ Real-Time System. Forty cycles of PCR were performed: initial enzyme activation and template denaturation at $95{ }^{\circ} \mathrm{C}$ for $10 \mathrm{~min}$ was followed by denaturation at $95{ }^{\circ} \mathrm{C}$ for $10 \mathrm{~s}$, annealing at $63{ }^{\circ} \mathrm{C}$ (PPM1D) or $58{ }^{\circ} \mathrm{C}\left(\beta\right.$-actin) for $30 \mathrm{~s}$, and an extension phase at $72{ }^{\circ} \mathrm{C}$ for $30 \mathrm{~s}$ followed by melting curve analysis. Ct values were used for quantification. All assays were $95-105 \%$ efficient. The relative levels of mRNA were calculated by the $2^{-\Delta \Delta \mathrm{Ct}}$ method.

\section{Lentivirus transfection}

Lentivirus vectors expressing scrambled shRNA (5-RTTCTCCGAACGTGTCACGT-3') and shRNA targeting PPM1D (5'-CCCTTCTCGTGTTTGCTTAAA-3') were purchased from GenePharma (Shanghai, China), and transfection was performed according to the manufacturer's protocol. The transfection efficiency was assessed by FL-1 channel detection of fluorescence generated from GFP-labeled shRNAs.

\section{Reagents}

The specific inhibitors of Wip1 (GSK2830371), p38 (SB202190) and Mdm2 (NVP-CGM097) were purchased from Selleckchem (Houston, USA), along with the proteasome inhibitor (MG-132). Dimethyl sulfoxide (DMSO, Sigma Aldrich, St. Louis, USA) served as a solvent.

\section{Flow cytometry}

HTR8/SVneo cells were plated in 6-well plates at a density of $1 \times 10^{5}$ cells/well. After culturing for 48 $\mathrm{h}$, the cells were washed twice with ice-cold PBS. Then, $1 \times 10^{6}$ cells were transferred into Annexin V-FITC and PI binding buffer (BD Biosciences, San Jose, USA) for $20 \mathrm{~min}$. The cells were then analyzed by an FCM Vantage SE flow cytometer (BD Biosciences, San Jose, CA, USA).

\section{Coimmunoprecipitation (Co-IP)}

Cell lysates were collected using binding buffer (50 mM Tris, $150 \mathrm{mM} \mathrm{NaCl}, 0.1 \%$ TritonX-100, pH 7.5) after treatments, and the lysates were immunoprecipitated with $3 \mu \mathrm{g}$ of antibody against p53 (Cell Signaling Technology, Danvers, USA) for 15 min before coupling to Protein A/G Magnetic Beads (Selleckchem, Houston, USA) overnight at $4^{\circ} \mathrm{C}$. The eluted antigen was obtained after $13000 \mathrm{~g}$ centrifugation for $10 \mathrm{~min}$ before SDSPAGE was performed as described in immunoblotting.

\section{Statistical analysis}

Quantitative data are shown as the mean \pm SEM. Statistical analyses were processed with Prism6 (GraphPad Software, San Diego, USA). The differences between the two groups were analyzed by independent t-test assuming a normal distribution and equal variance while Welch's t-test was used under conditions when equal variance was not assumed. Statistical comparisons among multiple groups were evaluated by 


\section{Cellular Physiology Cell Physiol Biochem 2019;52:315-335 \\ \begin{tabular}{ll|l} 
and Biochemistry $10.33594 / 000000023$ & C 2019 The Author(s). Published by \\
Published online: 28 February 2019 & Cell Physiol Biochem Press GmbH\&Co. KG
\end{tabular} \\ Tan et al.: p38-Wip1 Loop Regulates p53 in Trophoblast}

One-way ANOVA. Parametric tests were applied if normality and homogeneity of variance assumptions were satisfied; otherwise, the equivalent nonparametric test was used. A value of $p<0.05$ was considered statistically significant.

\section{Results}

\section{Clinical characteristics}

Clinical information on normal $(n=15)$ and $\mathrm{PE}(\mathrm{n}=13)$ pregnant women that participated in this study are summarized in Table 1 . There was no difference in maternal age, body mass index (BMI) and gestational age (GA) between the two groups, while systolic blood pressure $(165.20 \pm 2.19 \mathrm{mmHg}$ vs. $100.80 \pm 2.53 \mathrm{mmHg}, \mathrm{p}<0.0001)$, diastolic blood pressure $(114.50 \pm 2.02 \mathrm{mmHg}$ vs. $74.73 \pm 1.72 \mathrm{mmHg}, \mathrm{p}<0.0001)$, and $24 \mathrm{~h}$ proteinuria $(2.52 \pm 0.11 \mathrm{~g}$ vs. $0.05 \pm 0.01 \mathrm{~g}, \mathrm{p}<0.0001$ ) were significantly higher in the PE group compared to the controls. In addition, the PE group demonstrated a significant reduction in neonatal birth weight $(3584.00 \pm 144.10 \mathrm{~g}$ vs. $3083.00 \pm 132.80 \mathrm{~g}, \mathrm{p}<0.05)$ and placental weight $(524.40 \pm 9.30 \mathrm{~g}$ vs. $487.40 \pm 15.79, \mathrm{p}<0.05)$.

\section{Wip1 is predominantly expressed in trophoblasts in placenta}

First, the expression patterns of Wip1 in placental tissues during different stages of gestation were determined by IHC staining. As shown in Fig. 1A, in first-trimester placental villi Wip1 is mainly expressed in CTBs and STBs (Fig. 1Aa). Specifically, Wip1 is prominently expressed in EVTs and trophoblast columns (TC), as well as decidua (Fig. 1Ag-h), where they are costained with HLA-G (Fig. 1Ab and g). Similarly, in term placenta, Wip1 protein is barely observed in endothelial cells but is mainly expressed in trophoblasts (Fig. 1Ad-f). The distribution of Wip1 in the placenta suggests a potential role of the protein in the regulation of trophoblastic function.

Wip1 is upregulated in placentas from pregnancies complicated by $P E$ and in vitro trophoblast PE models

To investigate the role of Wip1 in trophoblasts and in the development of PE, we then examined Wip1 expression levels in PE and normal placentas and found that both mRNA and protein levels of Wip1 were significantly elevated in PE term placentas (Fig. 1B-C). Consistently, upregulation of Wip1 was also observed in HTR8/SVneo cells after treatment with HII or SIB (Fig. 1D), both of which effectively induced energetic crisis in trophoblast cells as the phosphorylation levels of AMPK and ACC were elevated (Fig. 1E-F). The results suggest that Wip1 overexpression in trophoblasts may be associated with the development of PE.

Wip1 is required for p38 activation and p53 dephosphorylation in trophoblasts under conditions of hypoxia

To ascertain the regulatory effect of Wip1 on p38 in trophoblasts during hypoxia, a shRNA targeting PPM1D, which led to a $51.16 \%$ reduction in Wip1 protein levels (Fig. 2AB), was transfected into HTR8/

SVneo cells during various in vitro hypoxic conditions. As shown in Fig. 2C, p-p38 ${ }^{\text {Thr180/ }}$ Tyr182 was significantly elevated by HII, while total $\mathrm{p} 38$ remained unchanged, but such activation of p38 was completely blocked in the presence of either a Wip1 inhibitor or shWip1. Accordingly, cl-cas9

Table 1. Clinical characteristics of subjects. GA and proteinuria were analyzed by Welch's t-test, and others were analyzed by student's t-test. ${ }^{*} \mathrm{P}<0.05,{ }^{* * * *} \mathrm{P}<0.0001$

\begin{tabular}{lcc}
\hline Category & Normal $(\mathrm{n}=15)$ & Preeclampsia $(\mathrm{n}=13)$ \\
\hline Pregnant age (years) & $27.20 \pm 1.12$ & $26.23 \pm 1.12$ \\
Body mass index (BMI, kg/m²) & $24.31 \pm 0.25$ & $23.55 \pm 0.31$ \\
Gestational age (GA, weeks) & $37.01 \pm 0.14$ & $36.28 \pm 0.41$ \\
Proteinuria (g/24h) & $0.05 \pm 0.01$ & $2.52 \pm 0.11^{* * * *}$ \\
Systolic blood pressure (mmHg) & $100.80 \pm 2.53$ & $165.20 \pm 2.19^{* * * *}$ \\
Diastolic blood pressure (mmHg) & $74.73 \pm 1.72$ & $114.50 \pm 2.02^{* * * *}$ \\
Placental weight (g) & $524.40 \pm 9.30$ & $487.40 \pm 15.79^{*}$ \\
Neonatal birth weight $(\mathrm{g})$ & $3584.00 \pm 144.10$ & $3083.00 \pm 132.80^{*}$ \\
\hline
\end{tabular}


Fig. 1. Expression pattern of Wip1 is altered in PE placentas and trophoblastic PE models. A. IHC staining of CK7, CD31, HLA-G, and Wip1 in villous (a-c), term placental (d-f) and decidual $(\mathrm{g}-\mathrm{h})$ tissue from healthy pregnancies, to assess the expression patterns of Wip1 in endothelial cells (ECs), cytotrophoblasts (CTBs), syncytiotrophoblasts (STBs), extravillous trophoblasts (EVTs), and trophoblast columns (TCs). Scale bar, $200 \mu \mathrm{m}$; B. The mRNA levels of Wip1 in normal and PE placentas, $n=7$, ${ }^{*} \mathrm{p}<0.05$, Student's t-test; $\mathrm{C}$. The representative Western blot and quantification of Wip1 protein in normal and PE placentas, $\mathrm{n}=7,{ }^{* * *} \mathrm{P}<0.001$, Student's t-test; D. IF staining of Wip1 (green) in HTR8/SVneo cells after $24 \mathrm{~h}$ of HII or SIB treatment, normoxia was included as control. Nuclei were counterstained by DAPI (blue). Scale bar, $100 \mu \mathrm{m}$; E-F. Phosphorylation levels of AMPK $\alpha$ and ACC, and Wip1 protein expression in HTR8/SVneo cells after $24 \mathrm{~h}$ of HII (E) and SIB (F) treatments were examined by Western blotting. $\mathrm{n}=4,{ }^{*} \mathrm{P}<0.05,{ }^{*} \mathrm{P}<0.01,{ }^{*} * \mathrm{P}<0.001$, Student's t-test. Experiments were performed in triplicate.

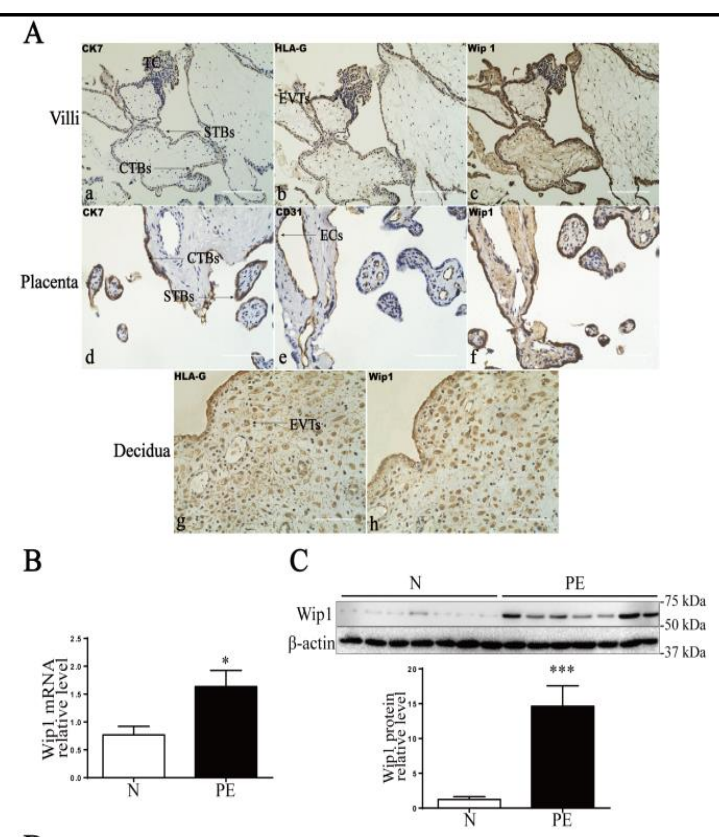

D

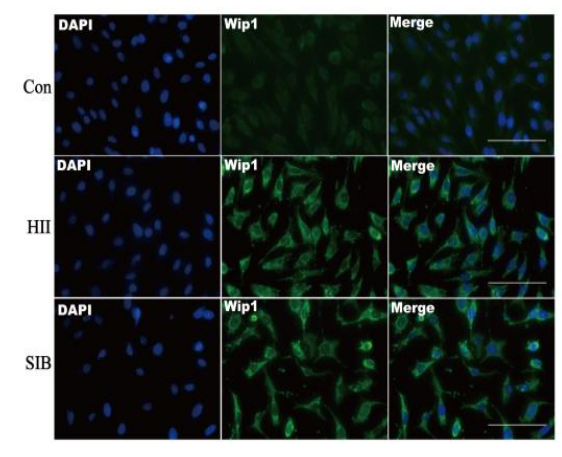

E
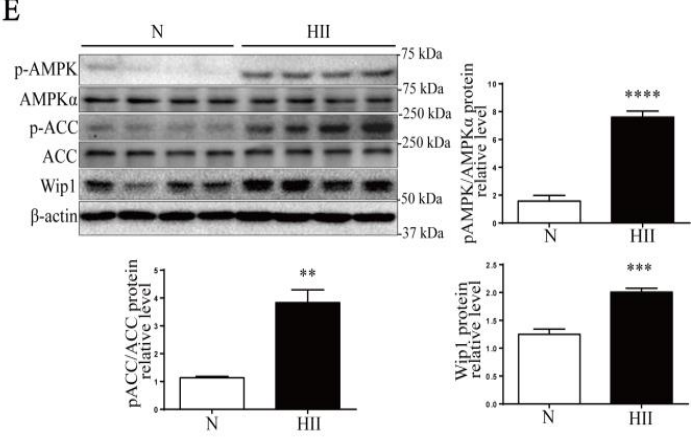

F
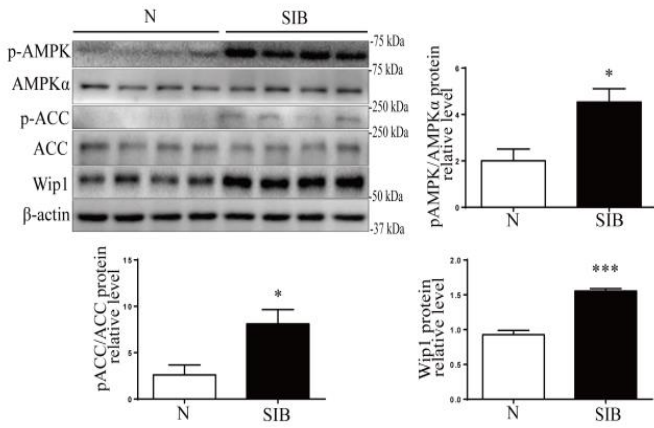
Fig. 2. Wip1 activates p38 and dephosphorylates p53 in trophoblasts under conditions of hypoxia. A: Lentiviral transfection efficiency was examined by FCM and IF. Scale bar $400 \mu \mathrm{m}$; B: Wip1 protein expression was confirmed by western blotting, $n=4$, ${ }^{*} \mathrm{P}<0.05$ vs. scrambled shRNA, one-way ANOVA, Dunnett-t multiple comparison test; C-D. Representative Western blots

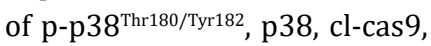
Mdm2, p-p53 ${ }^{\text {Ser15, }}$ and p53 in HTR8/SVneo cells after 24 $h$ of HII (A) or SIB (B) in the presence of $20 \mu \mathrm{M}$ GSK2830371 (GSK), DMSO (0.1\%), shWip1, or scrambled shRNA (MOI=50). $\mathrm{n}=4, \quad\left({ }^{*} \mathrm{P}<0.05, \quad{ }^{*} \mathrm{P}<0.01\right.$, $* * * \mathrm{P}<0.001, * * * * \mathrm{P}<0.0001$, oneway ANOVA, Sidak's multiple comparisons test. Experiments were performed in triplicate.

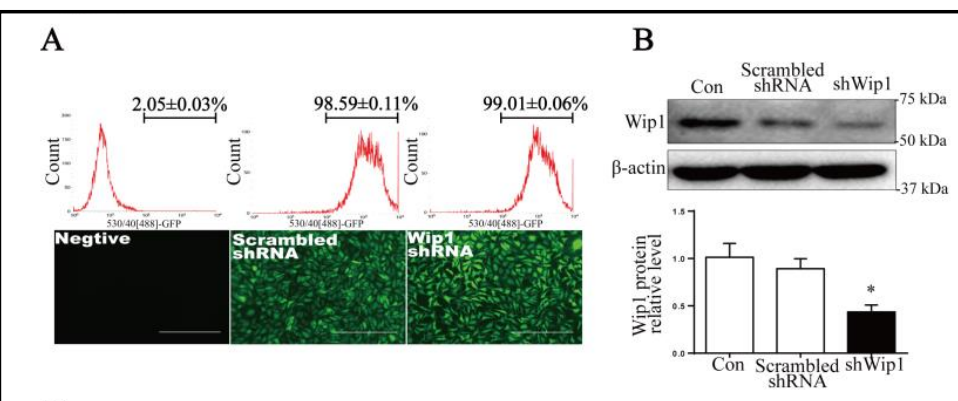

C

HII
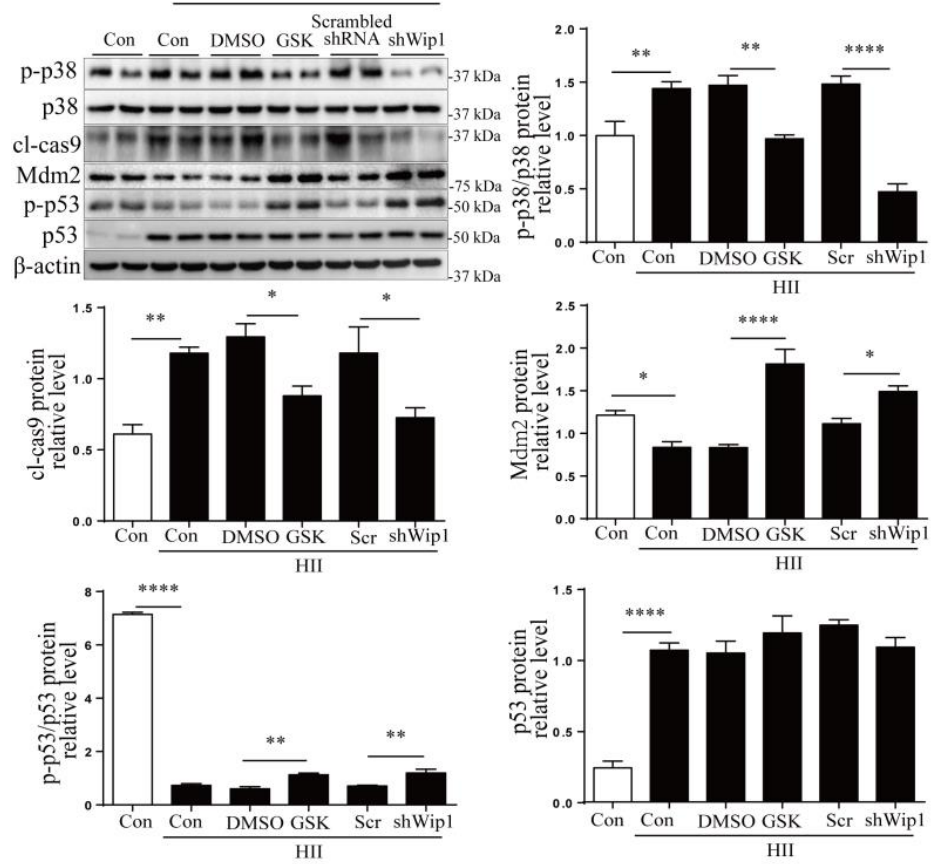

D
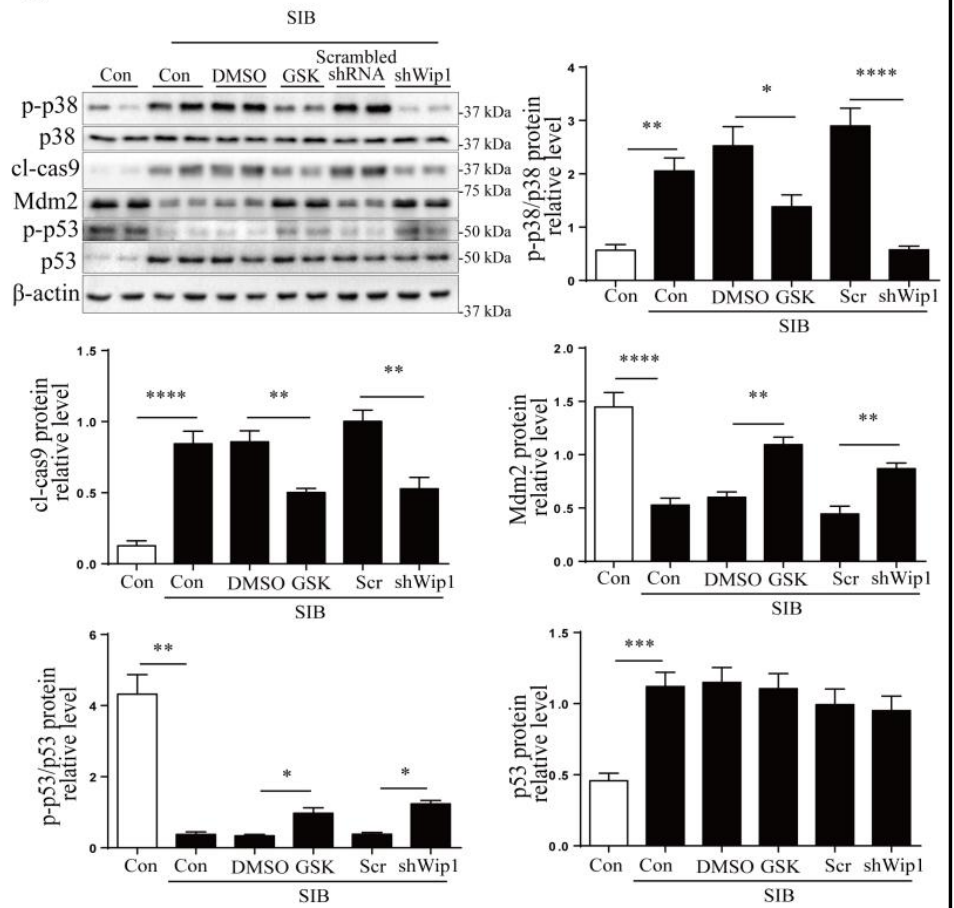


\section{Cellular Physiology Cell Physiol Biochem 2019;52:315-335 \\ \begin{tabular}{ll|l} 
and Biochemistry $10.33594 / 000000023$ & C 2019 The Author(s). Published by \\
Published online: 28 February 2019 & Cell Physiol Biochem Press GmbH\&Co. KG
\end{tabular} \\ Tan et al.: p38-Wip1 Loop Regulates p53 in Trophoblast}

was also significantly increased by HII, but levels declined if Wip1 activity or expression was suppressed. Moreover, a putative downstream target of Wip1, p-p53 ${ }^{\operatorname{Ser} 15}[26,27]$, was significantly reduced in HTR8/SVneo cells during HII, while Wip1 knockdown or GSK2830371 treatment rescued p53 phosphorylation at Ser15. It is known that phosphorylation of p53 at Ser15 reduces the interaction between p53 and its negative regulator, the oncoprotein Mdm2 [20]. Wip1 expression may thus be positively correlated with p53-Mdm2 interaction through dephosphorylation of p53. We then detected p53 in trophoblast. Intriguingly, p53 expression was dramatically enhanced by HII treatment, which was opposite to the observed change in p-p53 ${ }^{\text {Ser15 }}$, and further manipulation of Wip1 did not show any effect on the total protein levels of p53. However, Mdm2 was decreased by HII; recovery was demonstrated by additional GSK2830371 treatment or shWip1 transfection. Similar effects of Wip1 on p-p38 ${ }^{\text {Thr180/Tyr182 }}$, p38, p-p53 ${ }^{\text {Ser15 }}$, p53, Mdm2 and cl-cas9 were observed in SIB induced in vitro trophoblast PE model (Fig. 2D). These results suggest that persistent hypoxia augments p-p38 ${ }^{\text {Thr180/Tyr182 }}$ and cl-cas9, as well as decreases p-p53 ${ }^{\text {Ser15 }}$ and Mdm2, in trophoblast in a Wip1-dependent manner. Most importantly, our data suggest that Wip1 negatively regulates Ser15-phosphorylation-dependent p53 stabilization in trophoblasts during hypoxia.

\section{Inhibition of Wip1 attenuates hypoxia-induced apoptosis in HTR8/SVneo cells}

The roles of $\mathrm{p} 53$ and cl-cas 9 in the regulation of cell apoptosis have been extensively studied. To verify the signaling alterations observed in our Western blotting experiments, we measured the viability of HTR8/SVneo by FCM and found that either HII or SIB significantly elevated the apoptosis of HTR8/SVneo cells, while inhibition or down-regulation of Wip1 largely blocked hypoxia-induced trophoblastic apoptosis (Fig. 3A-C); this is consistent with the changes in apoptotic signaling discussed above.

Wip1 is required for $p 53-M d m 2$ interaction in trophoblast

Phosphorylation at Ser15 stabilizes p53 by interfering with its binding to Mdm2 [20]. Therefore, to further ascertain the involvement of Wip1 in p53-Mdm2 interaction in trophoblasts, the protein-protein interaction between p53 and Mdm2 were examined by co-IP. As shown in Fig. 3D, p53 physically interacts with Mdm2 in HTR8/SVneo cells under various hypoxic conditions, and inhibition of Wip1 by either shRNA or GSK2830371 resulted in significantly reduced binding between Mdm2 and p53, indicating that Wip1 is critical for the formation of the p53-Mdm2 complex. These results suggest that the elevation of Wip1 induced by hypoxic stress may enhance Mdm2-mediated p53 degradation through the inhibition of p53 phosphorylation at Ser 15 , thus providing a regulatory machinery to confine p53 accumulation, which may prevent excessive trophoblastic apoptosis during hypoxia.

p38 is required by hypoxia-induced Wip1 expression and Mdm2-dependentp53 degradation

To investigate whether p38 activation is involved in the regulatory effect of Wip1 on p53 stabilization and consequent apoptosis under hypoxia, the p38 inhibitor SB202190 was administered in hypoxic HTR8/SVneo cells. Surprisingly, inhibition of p38 activity in hypoxia not only markedly suppressed p53 and cl-cas9 expression levels (Fig. 4) but also downregulated Wip1 expression, indicating the existence of a positive feedback loop around Wip1 and p38 in trophoblasts. Moreover, SB202190 treatment significantly enhanced Mdm2 and p-p53 $3^{\text {Ser15 }}$ in hypoxia. Collectively, these data imply that p38 regulates p53 stabilization and consequent caspase-mediated apoptosis in hypoxia mainly by modulating the levels of $\mathrm{Mdm} 2$ and p-p53 ${ }^{\mathrm{Ser} 15}$, both of which may directly impact Mdm2-dependent $\mathrm{p} 53$ degradation in trophoblast. 
Inhibition of Mdm2 degradation resulted in p53 destabilization and p38-Wip1 loop downregulation

p38 degrades Mdm2 via a ubiquitin-proteasomal pathway and thus stabilizes p53 in cancer cells $[28,29]$. However, such a regulatory pathway has yet to be validated in trophoblasts. Therefore, the proteasome inhibitor MG-132 was applied to HTR8/SVneo cells under conditions of hypoxia to investigate whether Mdm2 plays an important role in p53 homeostasis in trophoblast. Immunoblots demonstrated that MG-132 significantly enhanced

Fig. 3. Wip1 is required for hypoxia-induced p53-Mdm2 interaction and apoptosis in HTR8/SVneo cells. A-C. Apoptosis of HTR8/SVneo cells after 24 h of HII (A) or SIB (B) in the presence of GSK (20 $\mu \mathrm{M})$, DMSO (0.1\%), shWip1, or scrambled shRNA (MOI=50), were determined by FCM, and apoptosis rate was qualified by percentage of Q2 and Q3 quadrants (C). $\mathrm{n}=4,{ }^{*} \mathrm{P}<0.05$, ${ }^{* *} \mathrm{P}<0.01$, one-way ANOVA, Sidak's multiple comparisons test; D. Co-IP of Mdm2 and p53 in HTR8/SVneo cells after $24 \mathrm{~h}$ of HII or SIB treatment in the presence of GSK (20 $\mu \mathrm{M}$ ) or shWip1 (MOI=50). Experiments were performed in triplicate.

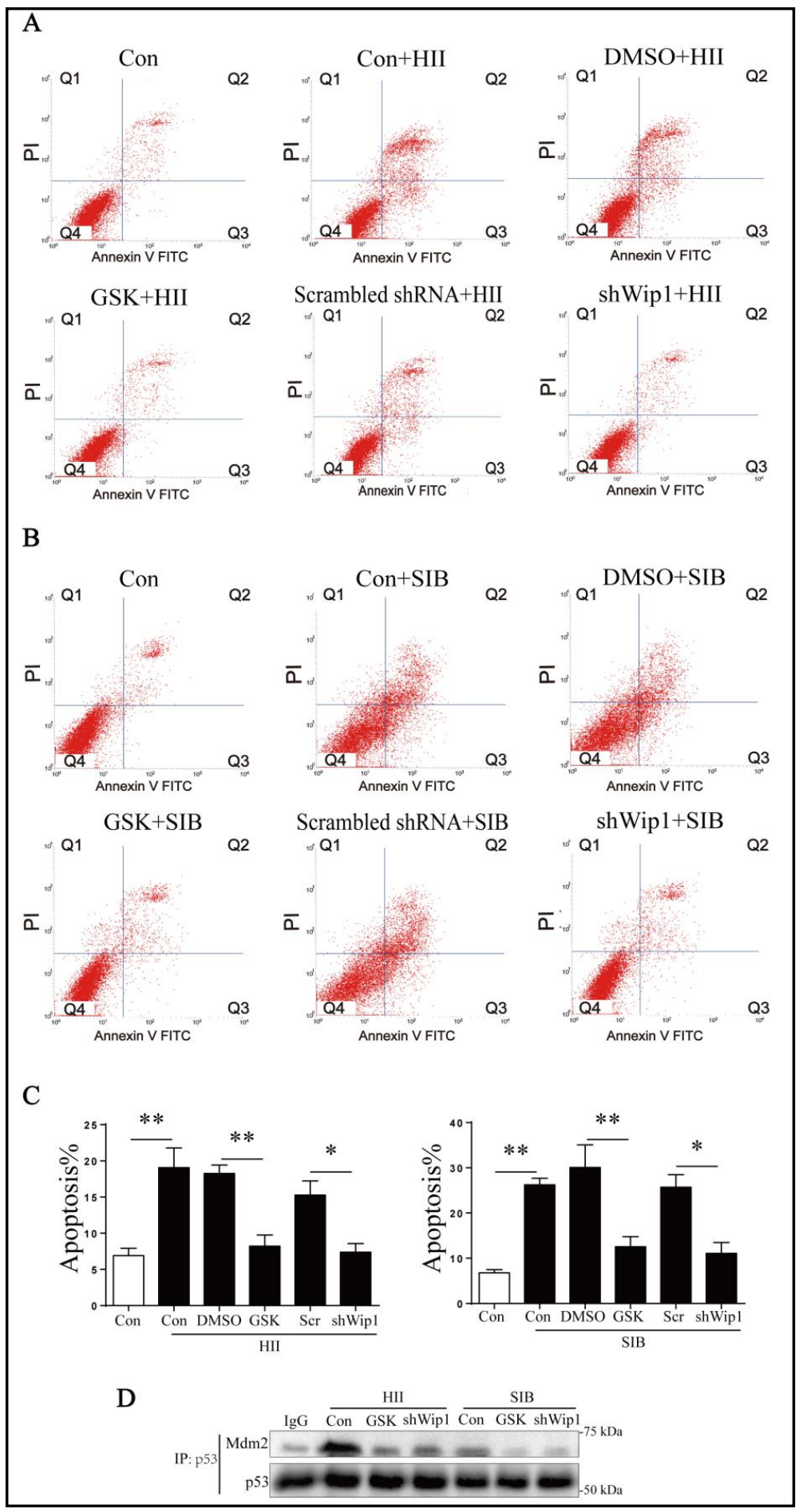




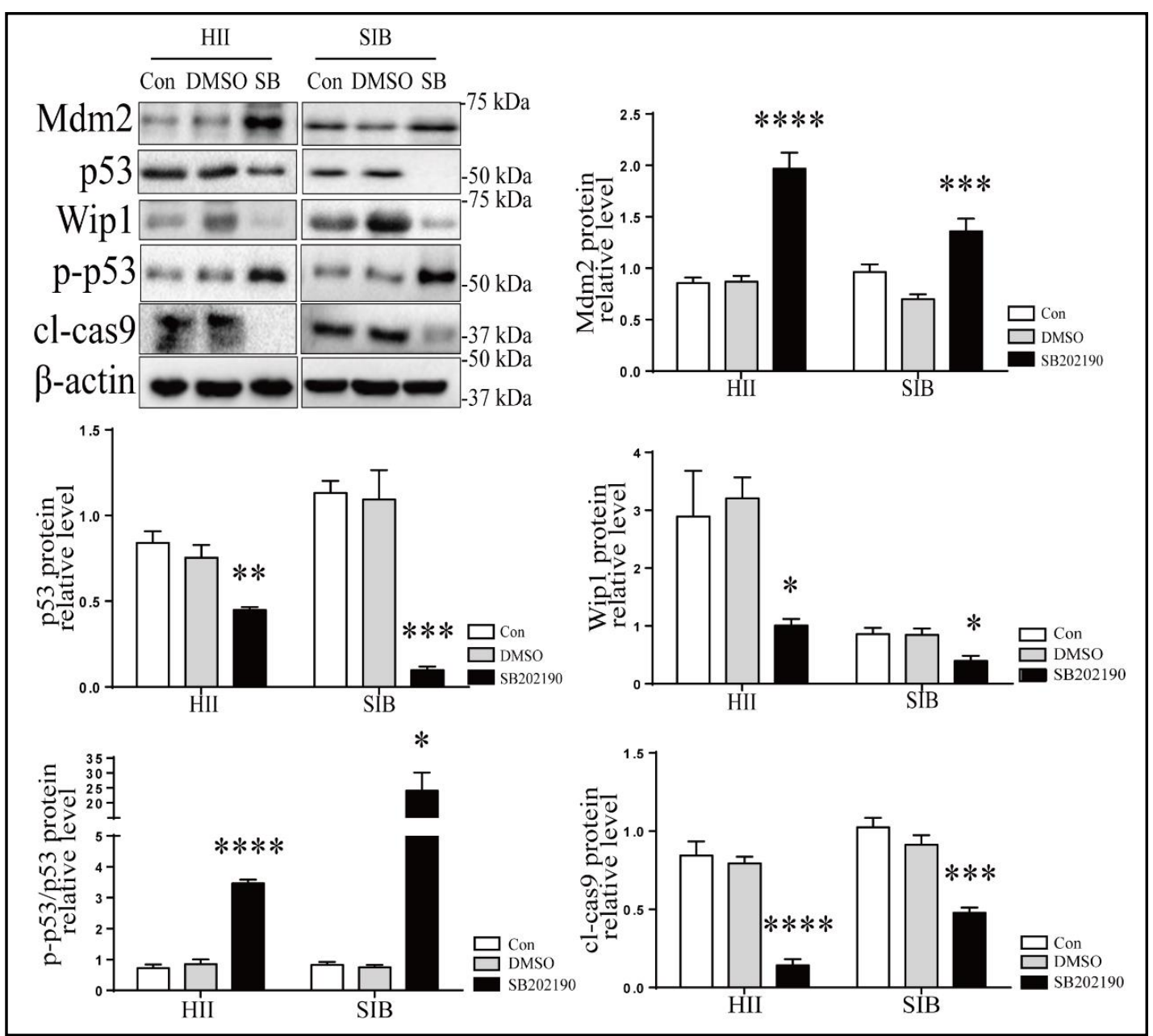

Fig. 4. p38 activity regulates p53 stabilization and Wip1 expression in hypoxia in HTR8/SVneo cells. Representative Western blotting of p-38-Wip1 loop consisting molecules in HTR8/SVneo cells after $24 \mathrm{~h}$ of HII or SIB in the presence of $4 \mu \mathrm{M}$ SB202190, Kruskal-Wallis test, Dunn's multiple comparison test for p-p53/p53 in SIB and one-way ANOVA, Dunnett-t multiple comparison test for others. $n=4$, $\beta$-actin was used as loading control. ${ }^{*} \mathrm{P}<0.05,{ }^{* *} \mathrm{P}<0.01,{ }^{* * *} \mathrm{P}<0.001,{ }^{* * * *} \mathrm{P}<0.0001$. Experiments were performed in triplicate.

Mdm2 in hypoxia; consistent with this finding, p53 accumulation was completely alleviated, even though p-p53 ${ }^{\text {Ser15 }}$ was significantly elevated (Fig. 5). Reduction in cl-cas9 suggested that trophoblastic apoptosis could be inhibited via Mdm2-dependent p53 degradation. Furthermore, p38 phosphorylation and Wip1 expression levels were suppressed in the presence of MG-132, thus confirming Mdm2 as a key mediating component of the p38-Wip1 loop, through the regulation of p53 stability.

Inhibition of p53 binding to Mdm2 resulted in p53 accumulation and p38-Wip1 loop upregulation

To further reveal the underlying mechanism of Mdm2 regulating p53 stabilization in the putative p38-Wip1 loop, HTR8/SVneo cells were treated with a highly potent selective inhibitor of Mdm2, NVP-CGM097 (denoted as NVP below), which specifically blocks the p53 binding-site of Mdm2 [30]. In the presence of NVP, the hypoxia-induced loss of Mdm2 was significantly rescued (Fig. 6). In accordance with this finding, p53 accumulation was further enhanced by NVP treatment. Taken together, these results suggest that p53 binding to Mdm2 resulted in degradation of p53 in trophoblasts. Consistent with p53 accumulation, cl-cas9 was upregulated by NVP administration. Furthermore, Wip1 expression was significantly 


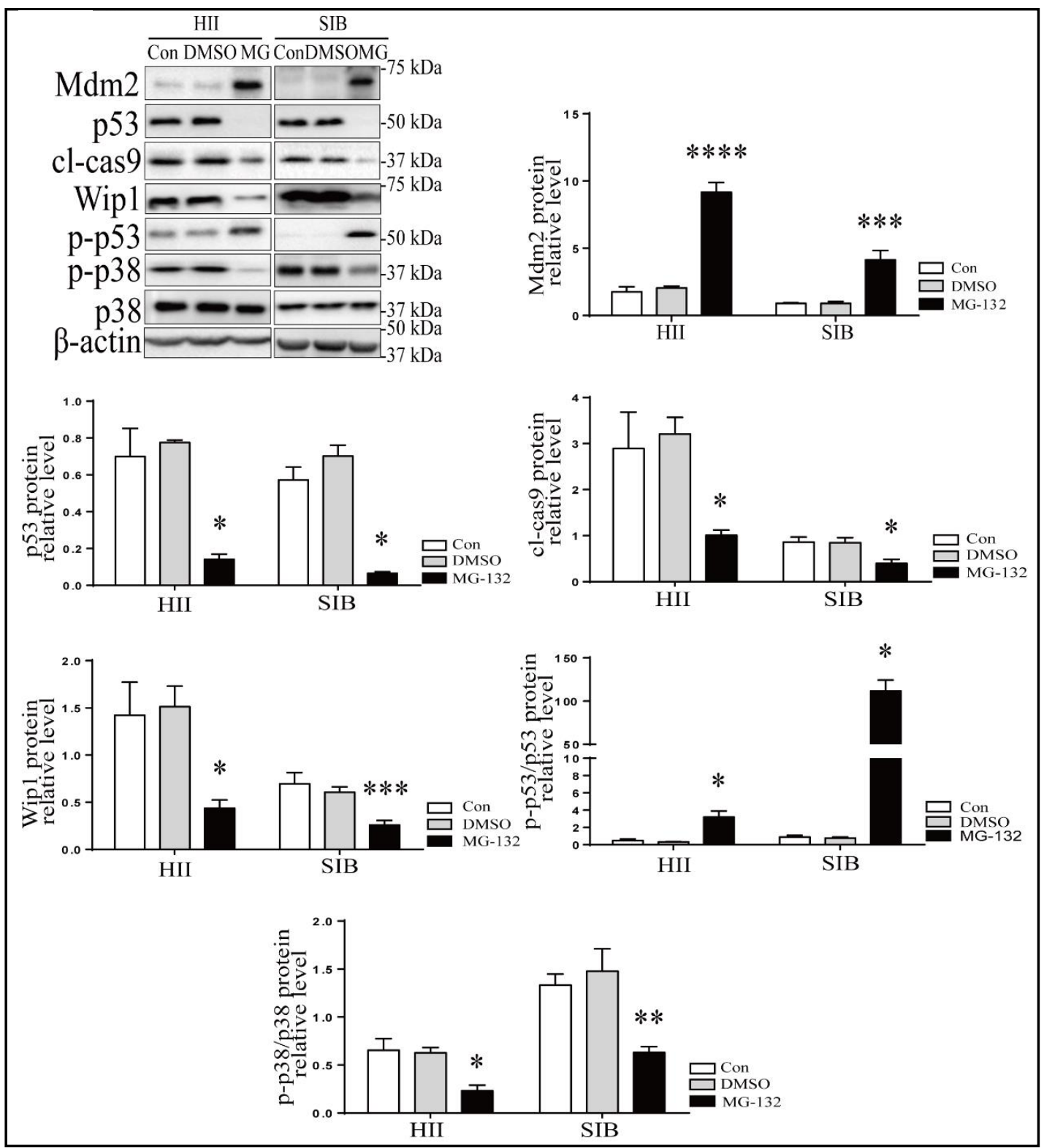

Fig. 5. Inhibition of Mdm2 degradation down-regulates p38-Wip1 loop. Representative Western blotting of p38-Wip1 loop consisting molecules in HTR8/SVneo cells after $24 \mathrm{~h}$ of HII or SIB in the presence of $6 \mu \mathrm{M}$ MG-132, Kruskal-Wallis test, Dunn's multiple comparison test for p-p53/p53 and one-way ANOVA, Dunnett-t multiple comparison test for others. $\mathrm{n}=4, \beta$-actin was used as loading control. ${ }^{*} \mathrm{P}<0.05, * * \mathrm{P}<0.01$, ${ }^{* * *} \mathrm{P}<0.001,{ }^{* * * *} \mathrm{P}<0.0001$. Experiments were performed in triplicate.

enhanced by the inhibition of Mdm2-p53 binding, either in normoxia or hypoxia; in accord with this finding, its substrate p-p53 $3^{\text {Ser15 }}$ was significantly lower under hypoxic conditions and further inhibited by NVP, while the level of p-p38 demonstrated similar changes with Wip1. These data are consistent with our previous results and confirm that p53 binding to Mdm2 is critical for p53 stabilization, and that the accumulation of p53 in trophoblasts during hypoxia due to interrupted Mdm2-dependent p53 degradation can be limited by the p38-Wip1 loop through the phosphorylation of p53. 


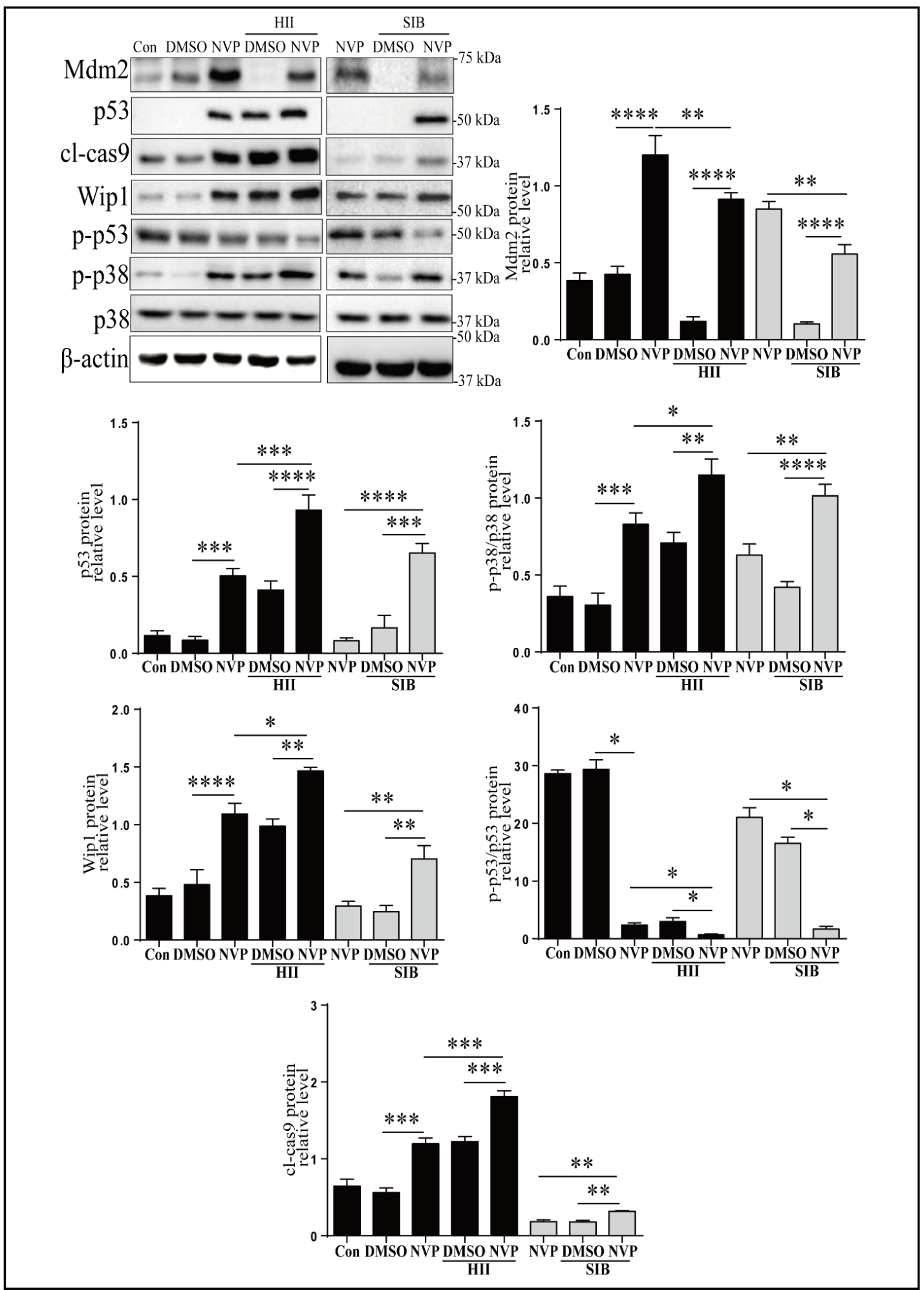

Fig. 6. Disruption of p53-Mdm2 interaction up-regulates p38-Wip1 loop. Representative Western blotting of p38-Wip1 loop consisting molecules in HTR8/SVneo cells pretreated with $2 \mu$ M NVP-CGM097 (NVP) for $6 \mathrm{~h}$ followed by $24 \mathrm{~h}$ of HII or SIB in fresh medium, Kruskal-Wallis test, Dunn's multiple comparison test for p-p53/p53 and one-way ANOVA, Sidak's multiple comparison test for others. $\beta$-actin was used as loading control. $\mathrm{n}=4, \beta$-actin was used as loading control. ${ }^{*} \mathrm{P}<0.05,{ }^{* *} \mathrm{P}<0.01,{ }^{* * *} \mathrm{P}<0.001,{ }^{* * * *} \mathrm{P}<0.0001$. Experiments were performed in triplicate. 


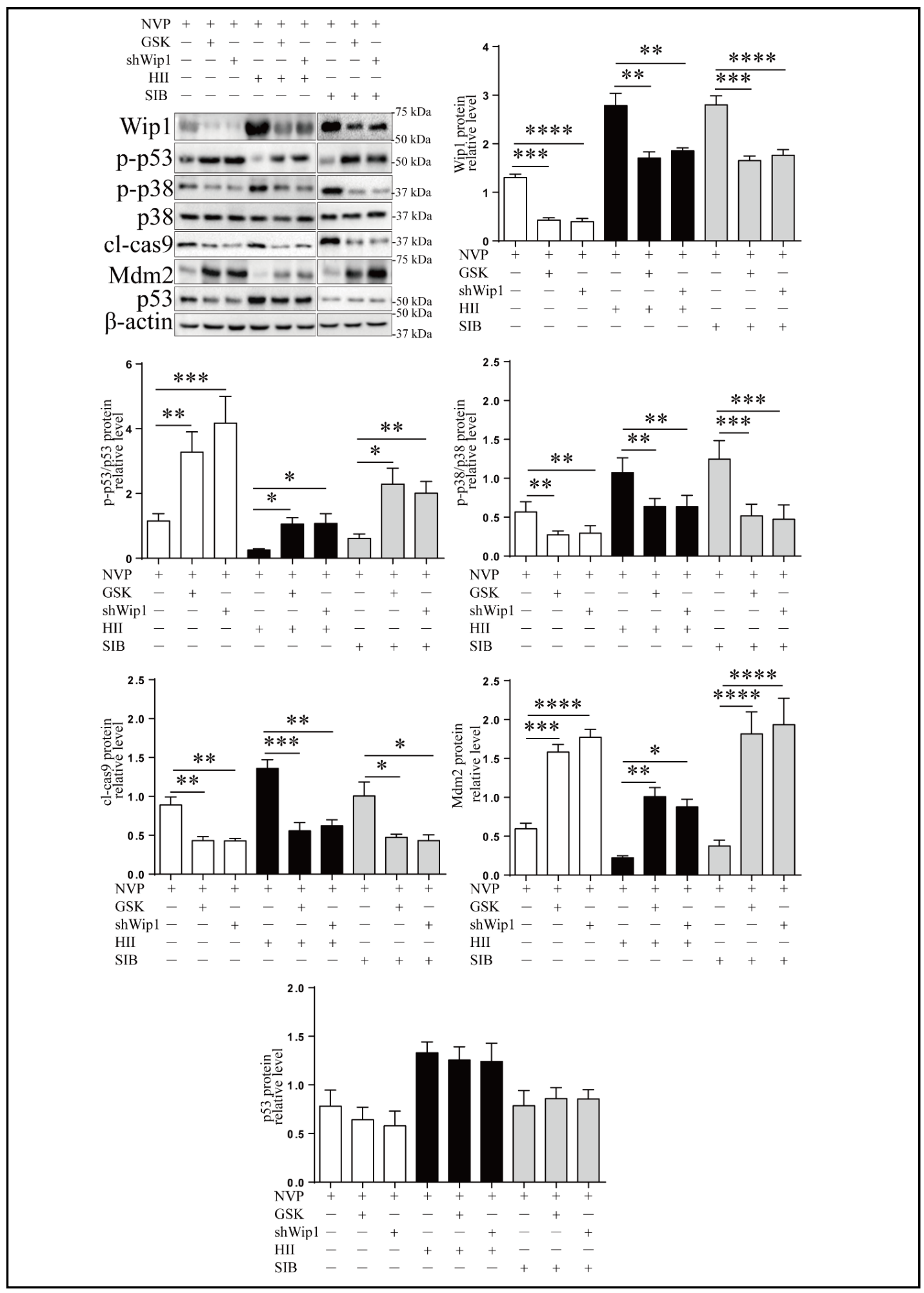

Fig. 7. Wip1 acts as a downstream effector of p53 in trophoblasts. Western blotting of p38-Wip1 loop consisting molecules in HTR8/SVneo cells pretreated with $2 \mu \mathrm{M}$ NVP for $6 \mathrm{~h}$, followed by $24 \mathrm{~h}$ of normoxia, HII, or SIB treatment in fresh medium along with $20 \mu \mathrm{M}$ GSK or shWip1 (MOI=50), Kruskal-Wallis test, Dunn's multiple comparison test for p-p53/p53 in HII and one-way ANOVA, Dunnett-t multiple comparison test for others. $\mathrm{n}=4, \beta$-actin was used as loading control. ${ }^{*} \mathrm{P}<0.05,{ }^{* *} \mathrm{P}<0.01,{ }^{* * *} \mathrm{P}<0.001,{ }^{* * * *} \mathrm{P}<0.0001$. Experiments were performed in triplicate. 
Wip1 is a downstream effector of $p 53$ in trophoblasts

In our study, inhibition or down-regulation of Wip1 in conditions of hypoxia did not influence p53 levels in trophoblasts, while manipulation of p53 stabilization resulted in alterations in Wip1 expression, suggesting that Wip1 might be a downstream effector of p53 in the p38-Wip1 loop. To further verify the regulatory order of components in the putative signaling loop, HTR8/SVneo cells were pretreated with NVP to break down all p53-Mdm2 interactions, followed by either pharmacological inhibition or shRNA interference of Wip1. The results demonstrated that the levels of Wip1, p-p38, and cl-cas9 were significantly enhanced, while p-p5 $3^{\text {Ser15 }}$ and Mdm 2 were suppressed by HII or SIB, even though the binding of p53 and Mdm2 had been demonstrated in advance (Fig. 7). However, the response of total p53 to Wip1 manipulation during hypoxia was blunted by NVP pretreatment. Taken together, these data confirmed that Wip1 elevation during hypoxia is more likely a downstream effect of p53 accumulation that passively feeds back on p53 stability in trophoblasts, rather than an upstream triggering event of p53 stabilization in response to hypoxic stress.

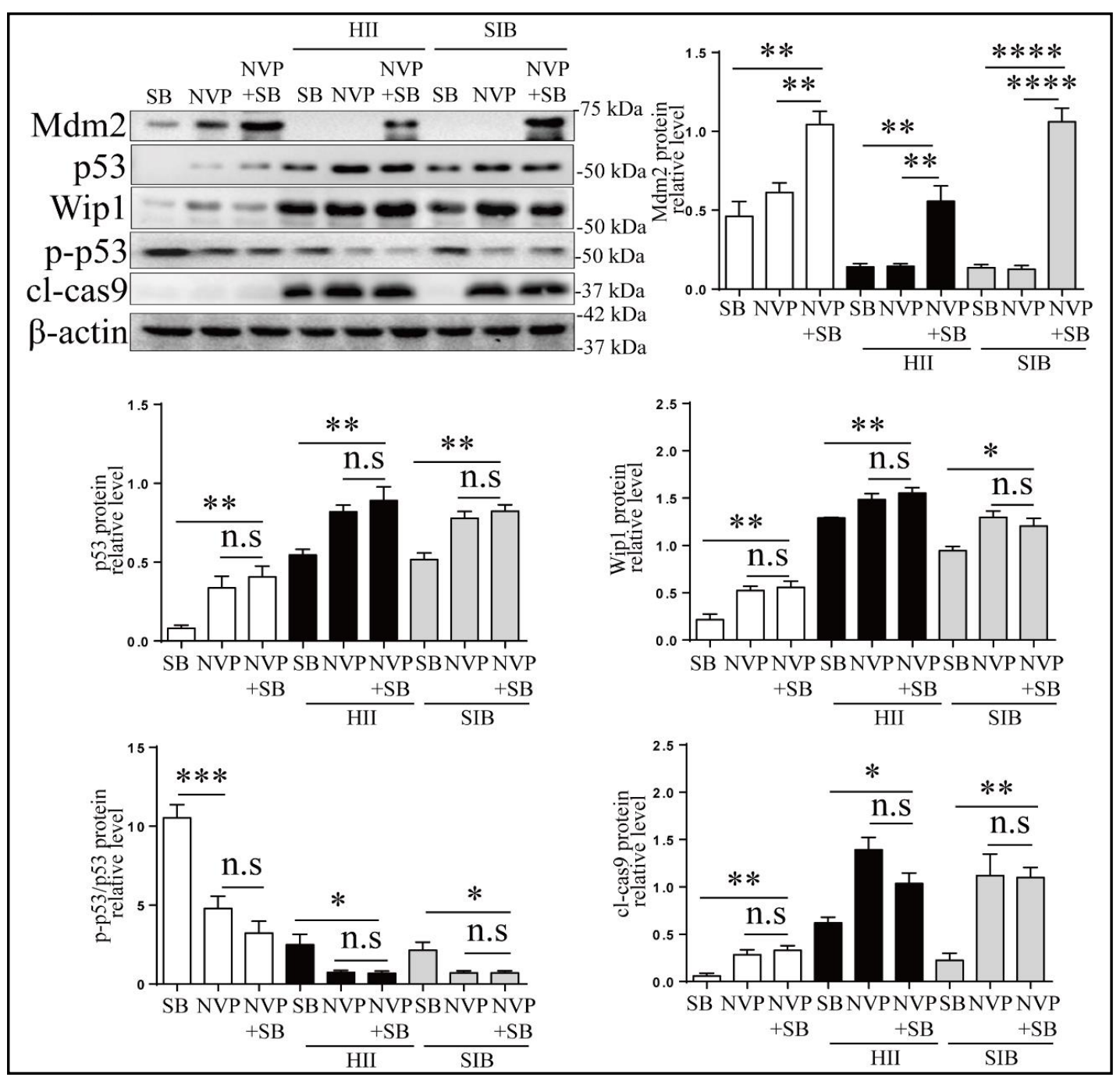

Fig. 8. p53-Mdm2 interaction is required for activation of the p38-Wip1 loop. Western blotting of p38-Wip1 loop consisting molecules in HTR8/SVneo cells incubated with $4 \mu \mathrm{M}$ SB202190 alone, $2 \mu \mathrm{M}$ NVP alone, or a combination of SB202190 and NVP in normoxia, HII and SIB for 24 h, Kruskal-Wallis test, Dunn's multiple comparison test for p-p53/p53 in HII and SIB, and one-way ANOVA, Dunnett-t multiple comparison test for others. $\mathrm{n}=4, \beta$-actin was used as loading control. ${ }^{*} \mathrm{P}<0.05$, ${ }^{* *} \mathrm{P}<0.01,{ }^{* * *} \mathrm{P}<0.001,{ }^{* * * *} \mathrm{P}<0.0001$. Experiments were performed in triplicate. 
p53-Mdm2 interaction is required for activation of the p38-Wip1 loop

To further investigate the role of p53-Mdm2 interaction in the p38-Wip1 loop, HTR8/ SVneo cells were subjected to the treatment of SB202190 alone, NVP alone, or a combination of SB202190 and NVP in hypoxia. SB202190 and NVP increased Mdm2 accumulation in trophoblasts under conditions of hypoxia (Fig. 8), indicating that both the p53-Mdm2 interaction and p38 activation contribute to Mdm2 destabilization. However, additional

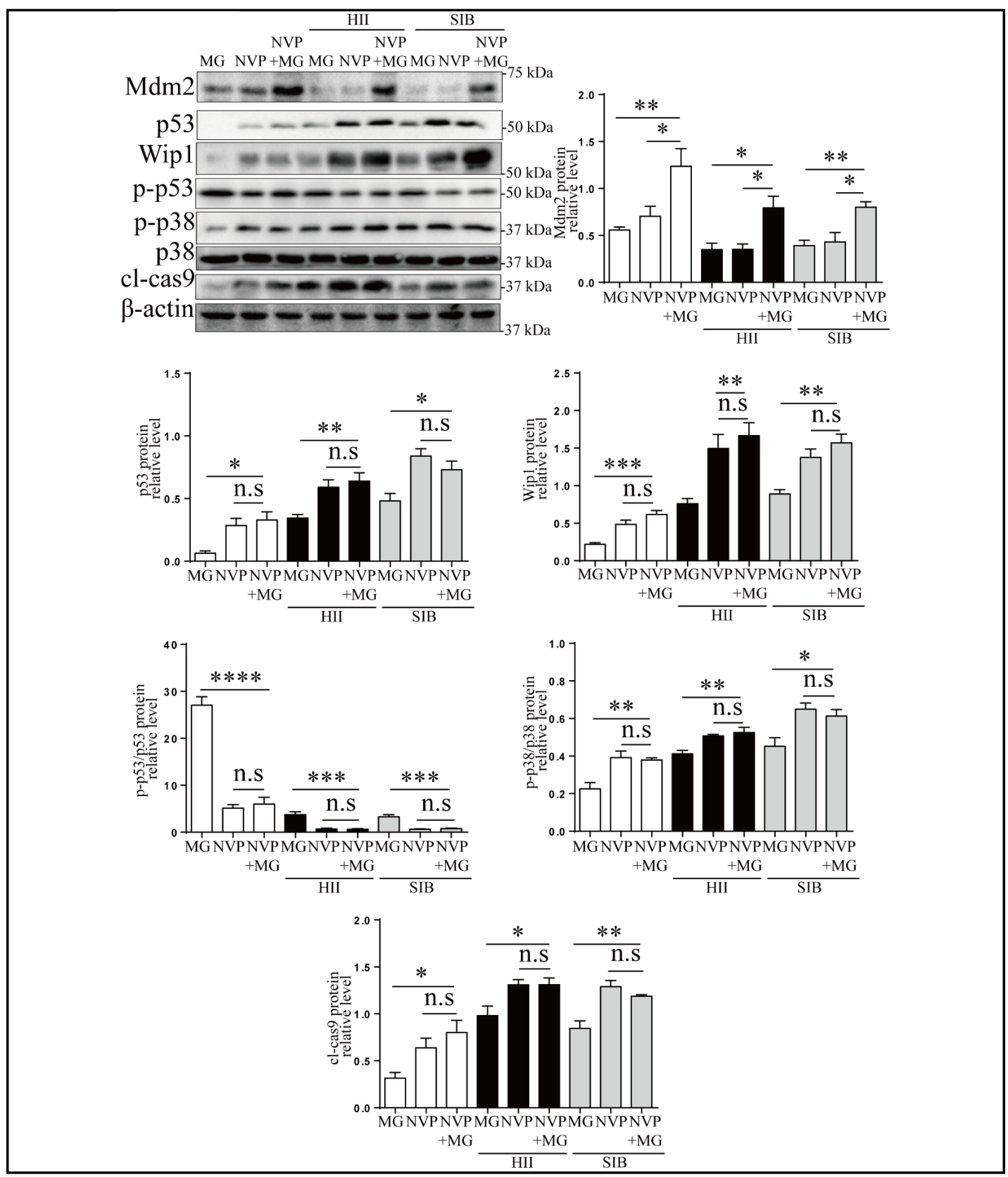

Fig. 9. The p53-Mdm2 interaction is critical in regulating the p38-Wip1 loop in trophoblasts. Western blotting of p38-Wip1 loop consisting molecules in HTR8/SVneo cells incubated with $6 \mu \mathrm{M}$ MG-132 alone, 2 $\mu \mathrm{M}$ NVP alone, or a combination of MG-132 and NVP in normoxia, HII and SIB for $24 \mathrm{~h}$, Kruskal-Wallis test, Dunn's multiple comparison test for p-p53/p53 in HII and SIB, and one-way ANOVA, Dunnett-t multiple comparison test for others. $\mathrm{n}=4, \beta$-actin was used as loading control. ${ }^{*} \mathrm{P}<0.05,{ }^{* *} \mathrm{P}<0.01,{ }^{* * *} \mathrm{P}<0.001$, $* * * * \mathrm{P}<0.0001$. Experiments were performed in triplicate. 


\section{Cellular Physiology Cell Physiol Biochem 2019;52:315-335 \\ \begin{tabular}{ll|l} 
and Biochemistry $10.33594 / 000000023$ & C 2019 The Author(s). Published by \\
Published online: 28 February 2019 & Cell Physiol Biochem Press GmbH\&Co. KG
\end{tabular} \\ Tan et al.: p38-Wip1 Loop Regulates p53 in Trophoblast}

SB202190 did not cause a further increase in p53, Wip1, and cl-cas9 compared to NVP treatment alone; nonetheless, NVP demonstrated more potent effects on p53 accumulation than SB202190 alone, suggesting that the p53-Mdm2 interaction is essential for transducing hypoxia-induced activation of p38 signaling to the downstream effectors of the p38-Wip1 loop in trophoblasts.

p53-Mdm2 interaction plays a more critical role in the regulation of the p38-Wip1 loop than Mdm2 destabilization

We found that either proteasome or p53-Mdm2-binding-mediated Mdm2 degradation impacts the p38-Wip1 loop in the trophoblast. However, the relative importance of these events in the regulation of the p38-Wip1 loop remains unclear. To clarify this issue, HTR8/ SVneo cells were subjected to treatments of NVP alone, MG-132 alone, or both together in hypoxia. Mdm2 expression in the MG-132 and NVP cotreated trophoblasts was significantly higher than that of the MG-132- or NVP-treated trophoblasts alone (Fig. 9). This indicated that either inhibition of the proteasome-mediated Mdm2 degradation or suppression of p53-Mdm2 binding resulted in Mdm2 upregulation. However, although the cotreatment with MG-132 and NVP resulted in a significantly higher p53 levels compared to treatment with MG-132 alone, there was no significant elevation in p53 expression compared to the group treated with NVP alone. Similar effects were observed for Wip1, p-p53 $3^{\text {Ser15, }}$ cl-cas9, and p-p38 ${ }^{\text {Thr180/Tyr182 }}$ These data indicate that blocking the p53-Mdm2 interaction is more efficient in potentiating the p38-Wip1 loop in trophoblasts than stabilization of Mdm2.

The p38-Wip1 loop is hyperactivated in human placentas from pregnancies complicated by $P E$

To validate the findings from our in vitro experiments, the putative p38-Wip1 loop was then examined in human term placentas. As shown in Fig. 10A, p-p38 ${ }^{\text {Thr180/Tyr182 }}$ was significantly augmented in PE placentas while Mdm2 was sharply down-regulated. In line with these results, p53 accumulation was observed in the PE group, and the levels of clcas 9 were also significantly elevated. Moreover, p-p53 $3^{\text {Ser15 }}$ was markedly decreased in PE placentas compared to normotensive controls. These data confirmed that PE placenta is associated with hyperactivation of the p38-Wip1 loop, and elevation of p53 and consequent cleavage of cas 9 may be responsible for the increased apoptosis in trophoblast cells that has long been observed in PE.

\section{Discussion}

The hypoxic microenvironment at the fetomaternal interface is thought to play a crucial role in the pathogenesis of $\mathrm{PE}[2,31-33]$. However, during 8-10 weeks of gestation, the oxygen concentration in the intervillous space is only $2-5 \%$ since the invasion of maternal uterine vessels by trophoblasts has just been initiated, and thus the fetomaternal circulation has yet to be fully established. Despite the fact that the oxygen levels will gradually increase to $10 \%$ due to vascular remodeling as pregnancy progresses, the placenta remains in a physiological hypoxic condition. Adaptation to the long-term low-oxygen environment confers hypoxia resistance on trophoblasts; therefore, establishment of a solid hypoxia model for trophoblasts is critical for elucidating the cellular and molecular basis of PE development.

In the present study, trophoblast cells were made hypoxic by using two approaches: HII treatment, a conventional approach of adjusting the concentration of oxygen to $1 \%$ in a cell incubator, and SIB treatment, which deprives HTR8/SVneo of dissolved oxygen by excessive sodium dithionate from potassium hydrogen and lactate. Most importantly, the hypoxia in trophoblast cells was confirmed by determination of the phosphorylation of AMPK, the master regulator of metabolism and sensor of ATP depletion [34, 35]; AMPK is much more 


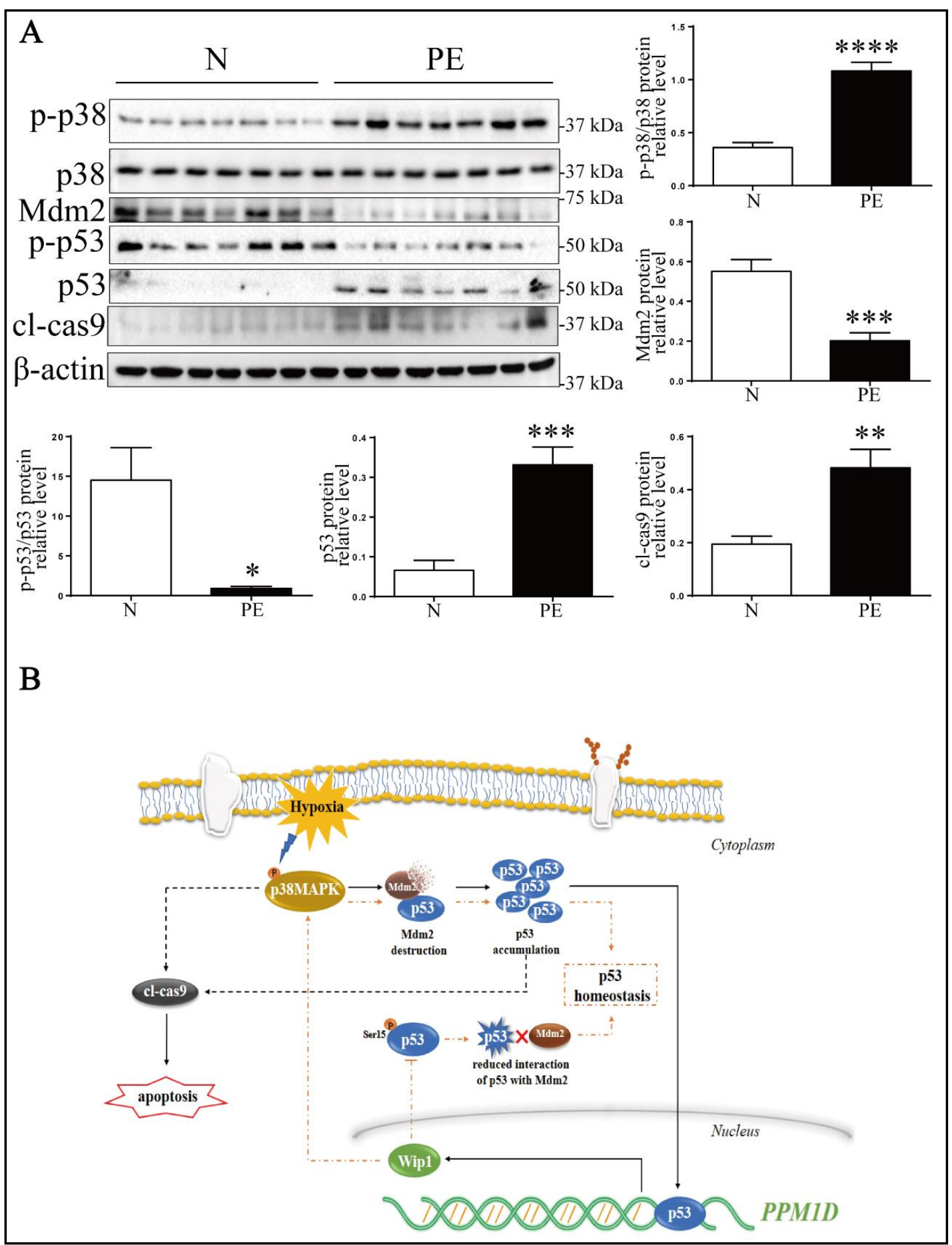

Fig. 10. The p38-Wip1 loop in normal and PE placentas. A. Western blotting of p38-Wip1 loop consisting molecules in Normal and PE complicated human placentas, Welch's t-test for p-p53/p53 and student's-t test for others, $\mathrm{n}=7$. $\beta$-actin was used as loading control, ${ }^{*} \mathrm{P}<0.05,{ }^{* *} \mathrm{P}<0.01,{ }^{* * *} \mathrm{P}<0.001,{ }^{* * * *} \mathrm{P}<0.0001$. Experiments were performed in triplicate; B. Working model of the p38-Wip1 feedback loop in trophoblasts. 
sensitive indicator of cellular hypoxia than HIF- $1 \alpha$, which is currently widely used as a biomarker for in vitro trophoblastic hypoxia $[35,36]$.

Placental apoptosis is exacerbated in placentas from pregnancies complicated by PE; this finding correlated with upregulation of p53, a well-studied tumor suppressor protein, as well as the down-regulation of its negative regulator, Mdm2 [8]. Although previous studies have shown that hypoxia induces p53 expression in placenta, the underlying mechanism underlying p53 regulation by hypoxic stress remains unknown [37]. In addition, previous work of our group and others have shown that PE placentas and low-oxygen treated trophoblast cells are associated with p38 hyperactivation, which compromises the invasion of trophoblast cells and increases the secretions of sFlt-1/sEng [38, 39]. Importantly, sustained p38 activation leads to elevation of cell apoptosis [40].

However, in the present work, we found that the enzyme that dephosphorylates p38, Wip1, which is supposed to be suppressed if p38 phosphorylation increased, was actually overexpressed in PE placentas. However, another substrate of Wip1, p-p53, demonstrates concordant alterations with Wip1 in the in vitro hypoxia trophoblast models. This phenomenon drew our attention to the role of Wip1 and its cross-talk with p38 and p53 in trophoblast apoptosis under hypoxia.

Both the pharmacological and genetic suppressions of Wip1 in HTR8/SVneo cells during hypoxia confirmed that hypoxia-induced p38 phosphorylation is Wip1-dependent; however, inhibition of p38 by SB2 02190 revealed that p38 activity is also required for hypoxia-induced Wip1 upregulation in trophoblast. This evidence suggested that p38 and Wip1 are positively correlated; therefore, a p38-Wip1 regulatory loop may exist in trophoblasts in response to hypoxia.

Moreover, our data showed that inhibition of Wip1 was significantly alleviated during hypoxia-induced trophoblastic apoptosis, which is opposite to its carcinogenic function in cancer cells [18]. To validate our finding, the effect of Wip1 on p53 was assessed. Although p53 phosphorylation was found to be decreased during hypoxia, in line with the alterations of Wip1 expression levels, the total p53 protein level remained relatively stable rather than unlimited augmentation in trophoblast cells. These facts indicate that the enhanced Wip1 expression and consequent dephosphorylation of p53 are likely to be a negative feedback for maintaining p53 homeostasis and are protective against excessive cell death.

In considering how Wip1 modulates p53 in trophoblasts, an MG-132-induced reduction in p53 led to suppressed Wip1 expression during hypoxia; in contrast, p53 accumulation by interfering with the p53-Mdm2 interaction markedly enhanced Wip1 expression in trophoblasts. Consistent with this finding, levels of $\mathrm{p}$-p $53^{\mathrm{Ser} 15}$ were negatively correlated with trophoblastic Wip1 levels in these experiments. The Wip1-induced loss of p-p53 $3^{\text {Ser15 }}$ is likely to be a compensatory feedback that prevents a burst of p53 accumulation; this feedback mechanism may be critical for maintaining p53 homeostasis and protecting against excessive apoptosis of trophoblasts and the loss of placental functions. These data further confirm that hypoxia results in p53 accumulation, which sequentially enhances Wip1 expression, in turn promoting p53 binding to Mdm2. Indeed, our co-IP data demonstrated that Wip1 is required for the p53-Mdm2 interaction, probably through dephosphorylation of p53 at Ser15[20].

To ascertain the initiating role of $\mathrm{p} 38$ activation in the putative $\mathrm{p} 38$-Wip1 loop, the binding between Mdm2 and p53 was disrupted by NVP prior to inhibition of p38 under conditions of hypoxia; we demonstrated that the physical interaction between p53 and Mdm2 is required for transmitting the signal of hypoxia-induced p38 activation to downstream effector Wip1. Lastly, the proposed p38-Wip1 loop has been validated in normal and PE human placentas, and the alterations of all signalling molecules were in accordance with those in hypoxiainduced HTR8/SVneo models of PE.

To the best of our knowledge, we are the first to report the interplay between p38 and Wip1 through p53-Mdm2 interaction in trophoblasts under a low-oxygen environment. However, although two different hypoxia-induced trophoblastic PE models were utilized in this study, the limitation of an in vitro PE model such as hypoxia reoxygenation [41] and continuous hypoxia [42] might not be able to fully elucidate the physiological changes of the 


\section{Cellular Physiology Cell Physiol Biochem 2019;52:315-335 \\ \begin{tabular}{ll|l} 
and Biochemistry & $\begin{array}{l}\text { DOl: 10.33594/000000023 } \\
\text { Published online: } 28 \text { February } 2019\end{array}$ & $\begin{array}{l}\text { C 2019 The Author(s). Published by } \\
\text { Cell Physiol Biochem Press GmbH\&Co. KG }\end{array}$ \\
\cline { 2 - 3 }
\end{tabular} \\ Tan et al.: p38-Wip1 Loop Regulates p53 in Trophoblast}

loop in vivo. Further validation of our findings by using Reduced Uterine Perfusion Pressure (RUPP) or sFlt-1 overexpression induced murine PE models [43, 44], could more precisely delineate the importance of p38-Wip1 loop in the pathogenesis of PE.

\section{Conclusion}

In summary, this study demonstrates a feedback regulatory loop between p38 and Wip1 in trophoblasts. Phosphorylation of p38 stabilizes p53 through deprivation of Mdm2 and/or disassociation of the p53-Mdm2 complex, both of which lead to p53-dependent apoptosis and the upregulation of Wip1. In turn, elevated Wip1 dephosphorylates p-p53 ${ }^{\text {Ser15, }}$ thus restoring the interaction between p53 and Mdm2, and consequent p53 degradation. Activation of the p38-Wip1 loop ultimately results in p53 homeostasis and protects against excessive apoptosis during hypoxia (Fig. 10B). Validation of these findings by using animal PE models could further ascertain the potential of this loop as an interventional target for the prevention and management of PE.

\section{Acknowledgements}

This work was supported by grants from Ministry of Science and Technology (2018YFC1004103, 2018YFC1002901), National Natural Sciences Foundation of China (81671488, 81871189, 81771613, 81520108013, 81801482, 81701479, 81701480), Chongqing Municipal Education Commission (CXTDX201601014), Chongqing Science and Technology Commission (cstc2017jcyjBX0045), Chongqing Entrepreneurship and Innovation Supporting Program for Returned Overseas Students (cx2017104), and Chongqing Research Innovation Program for Postgraduates (CYB17114). In addition, this study was supported by the "111 program" of the Ministry of Education P.R.C, State Administration of Foreign Experts Affairs P.R.C., and Key Lab of Birth Defects and Reproductive Health of National Health and Family Planning Commission P.R.C..

\section{Disclosure Statement}

The authors declare to have no competing interests.

\section{References}

1 Haider S, Meinhardt G, Saleh L, Fiala C, Pollheimer J, Knöfler M: Notch1 controls development of the extravillous trophoblast lineage in the human placenta. Proc Natl Acad Sci U S A 2016;113:E7710-E7719.

2 Red-Horse K, Zhou Y, Genbacev 0, Prakobphol A, Foulk R, McMaster M, Fisher SJ: Trophoblast differentiation during embryo implantation and formation of the maternal-fetal interface. J Clin Invest 2004;114:744-754.

- 3 Steegers EA, von Dadelszen P, Duvekot JJ, Pijnenborg R: Pre-eclampsia. Lancet 2010;376:631-644.

- 4 Heazell AE, Sharp AN, Baker PN, Crocker IP: Intra-uterine growth restriction is associated with increased apoptosis and altered expression of proteins in the p53 pathway in villous trophoblast. Apoptosis 2011;16:135-144.

- 5 Hung TH, Burton GJ: Hypoxia and reoxygenation: a possible mechanism for placental oxidative stress in preeclampsia. Taiwan J Obstet Gynecol 2006;45:189-200.

6 Heazell AE, Lacey HA, Jones CJ, Huppertz B, Baker PN, Crocker IP: Effects of oxygen on cell turnover and expression of regulators of apoptosis in human placental trophoblast. Placenta 2008;29:175-186. 


\section{Cellular Physiology Cell Physiol Biochem 2019;52:315-335 \begin{tabular}{ll|l|l|l}
\hline DOI: 10.33594/000000023 & (O) 2019 The Author(s). Published by \\
\hline
\end{tabular} and Biochemistry Published online: 28 February 2019 Cell Physiol Biochem Press GmbH\&Co. KG \\ Tan et al.: p38-Wip1 Loop Regulates p53 in Trophoblast}

7 Hung TH, Chen SF, Liou JD, Hsu JJ, Li MJ, Yeh YL, Hsieh TT: Bax, Bak and mitochondrial oxidants are involved in hypoxia-reoxygenation-induced apoptosis in human placenta. Placenta 2008;29:565-583.

8 Sharp AN, Heazell AE, Baczyk D, Dunk CE, Lacey HA, Jones CJ, Perkins JE, Kingdom JC, Baker PN, Crocker IP: Preeclampsia is associated with alterations in the p53-pathway in villous trophoblast. PLoS One 2014;9:e87621.

9 Coulthard LR, White DE, Jones DL, McDermott MF, Burchill SA: p38(MAPK): stress responses from molecular mechanisms to therapeutics. Trends Mol Med 2009;15:369-379.

10 Wang HY, Liu ZS, Qiu L, Guo J, Li YF, Zhang J, Wang TJ, Liu XD: Knockdown of Wip1 Enhances Sensitivity to Radiation in HeLa Cells Through Activation of p38 MAPK. Oncol Res 2014;22:225-233.

11 Feng Y, Liu F, Du Z, Zhao D, Cheng J, Guo W: Wip1 regulates SKOV3 cell apoptosis through the p38 MAPK signaling pathway. Mol Med Rep 2017;15:3651-3657.

12 Hu X, Wang P, Du J, Yang F, Tian Y, Shen X, Yang T, Zhang L, Zhao Y: Phosphatase Wip1 Masters IL-17producing Neutrophil-mediated Colitis in Mice. Inflamm Bowel Dis 2016;22:1316-1325.

13 Zhang L, Liu L, He Z, Li G, Liu J, Song Z, Jin H, Rudolph KL, Yang H, Mao Y, Zhang L, Zhang H, Xiao Z, Ju Z: Inhibition of wild-type p53-induced phosphatase 1 promotes liver regeneration in mice by direct activation of mammalian target of rapamycin. Hepatology 2015;61:2030-2041.

14 Ruan CS, Zhou FH, He ZY, Wang SF, Yang CR, Shen YJ, Guo Y, Zhao HB, Chen L, Liu D, Liu J, Baune BT, Xiao ZC, Zhou XF: Mice deficient for wild-type p53-induced phosphatase 1 display elevated anxiety- and depression-like behaviors. Neuroscience 2015;293:12-22.

- 15 Richter M, Dayaram T, Gilmartin AG, Ganji G, Pemmasani SK, Van Der Key H, Shohet JM, Donehower LA, Kumar R: WIP1 phosphatase as a potential therapeutic target in neuroblastoma. PLoS One 2015;10:e0115635.

16 Pechackova S, Burdova K, Benada J, Kleiblova P, Jenikova G, Macurek L: Inhibition of WIP1 phosphatase sensitizes breast cancer cells to genotoxic stress and to MDM2 antagonist nutlin-3. Oncotarget 2016;7:14458-14475.

17 Demidov ON, Timofeev 0, Lwin HN, Kek C, Appella E, Bulavin DV: Wip1 phosphatase regulates p53dependent apoptosis of stem cells and tumorigenesis in the mouse intestine. Cell Stem Cell 2007;1:180190.

18 Goloudina AR, Kochetkova EY, Pospelova TV, Demidov ON: Wip1 phosphatase: between p53 and MAPK kinases pathways. Oncotarget 2016;7:31563-31571.

19 Lu X, Nannenga B, Donehower LA: PPM1D dephosphorylates Chk1 and p53 and abrogates cell cycle checkpoints. Genes Dev 2005;19:1162-1174.

20 Shieh SY, Ikeda M, Taya Y, Prives C: DNA damage-induced phosphorylation of p53 alleviates inhibition by MDM2. Cell 1997;91:325-334.

21 Takekawa M, Adachi M, Nakahata A, Nakayama I, Itoh F, Tsukuda H, Taya Y, Imai K: p53-inducible wip1 phosphatase mediates a negative feedback regulation of p38 MAPK-p53 signaling in response to UV radiation. EMBO J 2000;19:6517-6526.

22 American College of Obstetricians and Gynecologists, Task Force on Hypertension in Pregnancy: Hypertension in pregnancy. Report of the American College of Obstetricians and Gynecologists' Task Force on Hypertension in Pregnancy. Obstet Gynecol 2013;122:1122-1131.

23 Burton GJ, Sebire NJ, Myatt L, Tannetta D, Wang YL, Sadovsky Y, Staff AC, Redman CW: Optimising sample collection for placental research. Placenta 2014;35:9-22.

24 Deng Q, Chen Y, Yin N, Shan N, Luo X, Tong C, Zhang H, Baker PN, Liu X, Qi H: $\mathrm{N}$-acetylglucosaminyltransferase $\mathrm{V}$ inhibits the invasion of trophoblast cells by attenuating MMP2/9 activity in early human pregnancy. Placenta 2015;36:1291-1299.

25 Yang Y, Duan W, Jin Z, Yi W, Yan J, Zhang S, Wang N, Liang Z, Li Y, Chen W, Yi D, Yu S: JAK2/STAT3 activation by melatonin attenuates the mitochondrial oxidative damage induced by myocardial ischemia/ reperfusion injury. J Pineal Res 2013;55:275-286.

26 Xia Y, Yang Q, Gong X, Ye F, Liou YC: Dose-dependent mutual regulation between Wip1 and p53 following UVC irradiation. Int J Biochem Cell Biol 2011;43:535-544.

- 27 Meek DW: New developments in the multi-site phosphorylation and integration of stress signalling at p53. Int J Radiat Biol 1998;74:729-737. 


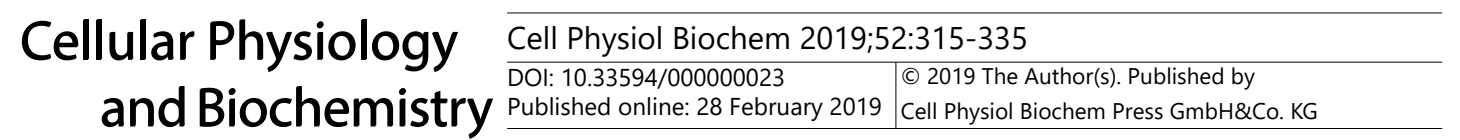

28 Bulavin DV, Saito S, Hollander MC, Sakaguchi K, Anderson CW, Appella E, Fornace AJ, Jr: Phosphorylation of human p53 by p38 kinase coordinates N-terminal phosphorylation and apoptosis in response to UV radiation. ЕMBO J 1999;18:6845-6854.

29 Holzer P, Masuya K, Furet P, Kallen J, Valat-Stachyra T, Ferretti S, Berghausen J, Bouisset-Leonard M, Buschmann N, Pissot-Soldermann C, Rynn C, Ruetz S, Stutz S, Chene P, Jeay S, Gessier F: Discovery of a Dihydroisoquinolinone Derivative (NVP-CGM097): A Highly Potent and Selective MDM2 Inhibitor Undergoing Phase 1 Clinical Trials in p53wt Tumors. J Med Chem 2015;58:6348-6358.

30 Tuuli MG, Longtine MS, Nelson DM: Review: Oxygen and trophoblast biology--a source of controversy. Placenta 2011;32:S109-118.

31 Schaaps JP, Tsatsaris V, Goffin F, Brichant JF, Delbecque K, Tebache M, Collignon L, Retz MC, Foidart JM: Shunting the intervillous space: new concepts in human uteroplacental vascularization. Am J Obstet Gynecol 2005;192:323-332.

32 Genbacev 0, Zhou Y, Ludlow JW, Fisher SJ: Regulation of human placental development by oxygen tension. Science 1997;277:1669-1672.

33 Landau D, Haghiac M, Minium J, Skomorovska-Prokvolit Y, Calabuig-Navarro V, O’Tierney-Ginn P: Activation of AMPK in Human Placental Explants Impairs Mitochondrial Function and Cellular Metabolism. Reprod Sci 2018:1933719118776803.

34 Skeffington KL, Higgins JS, Mahmoud AD, Evans AM, Sferruzzi-Perri AN, Fowden AL, Yung HW, Burton GJ, Giussani DA, Moore LG: Hypoxia, AMPK activation and uterine artery vasoreactivity. J Physiol 2016;594:1357-1369.

35 Banerjee P, Bhonde RR, Pal R: Diverse roles of metformin during peri-implantation development: revisiting novel molecular mechanisms underlying clinical implications. Stem Cells Dev 2013;22:29272934.

36 Liu X, Deng Q, Luo X, Chen Y, Shan N, Qi H: Oxidative stress-induced Gadd45alpha inhibits trophoblast invasion and increases sFlt1/sEng secretions via p38 MAPK involving in the pathology of pre-eclampsia. J Matern Fetal Neonatal Med 2016;29:3776-3785.

37 Shan N, Zhang X, Xiao X, Zhang H, Tong C, Luo X, Chen Y, Liu X, Yin N, Deng Q, Qi H: Laminin a4 (LAMA4) expression promotes trophoblast cell invasion, migration, and angiogenesis, and is lowered in preeclamptic placentas. Placenta 2015;36:809-820.

38 Murphy LO, Blenis J: MAPK signal specificity: the right place at the right time. Trends Biochem Sci 2006;31:268-275.

39 Leach RE, Kilburn BA, Petkova A, Romero R, Armant DR: Diminished survival of human cytotrophoblast cells exposed to hypoxia/reoxygenation injury and associated reduction of heparin-binding epidermal growth factor-like growth factor. Am J Obstet Gynecol 2008; DOI:10.1016/j.ajog.2008.01.009.

40 Luo R, Wang Y, Xu P, Cao G, Zhao Y, Shao X, Li YX, Chang C, Peng C, Wang YL: Hypoxia-inducible miR210 contributes to preeclampsia via targeting thrombospondin type I domain containing 7A. Sci Rep 2016;6:19588.

41 Fushima T, Sekimoto A, Minato T, Ito T, Oe Y, Kisu K, Sato E, Funamoto K, Hayase T, Kimura Y, Ito S, Sato H, Takahashi N: Reduced Uterine Perfusion Pressure (RUPP) Model of Preeclampsia in Mice. PLoS One 2016;11:e0155426.

42 Maynard SE, Min JY, Merchan J, Lim KH, Li J, Mondal S, Libermann TA, Morgan JP, Sellke FW, Stillman IE, Epstein FH, Sukhatme VP, Karumanchi SA: Excess placental soluble fms-like tyrosine kinase 1 (sFlt1) may contribute to endothelial dysfunction, hypertension, and proteinuria in preeclampsia. J Clin Invest 2003;111:649-658. 